\title{
Acoustic and Heat Release Signatures for Swirl Assisted Distributed Combustion
}

\author{
Ahmed E.E. Khalil and Ashwani K. Gupta* \\ Department of Mechanical Engineering, \\ University of Maryland, College Park, MD 20742, USA
}

\begin{abstract}
The acoustic signal and heat release fluctuations are examined from a swirl combustor using methane as the fuel. The focus was on flame stability and noise emission that have direct relevance in further developing distributed combustion for gas turbine applications and oxy-fuel combustion. Three regimes are examined in this paper, the first being a swirl mode at equivalence ratios between 0.9 and 0.55 . The second one being distributed combustion, achieved through $\mathrm{N}_{2} / \mathrm{CO}_{2}$ dilution to reach oxygen concentration below $15 \%$, fostering distributed reaction. The third was oxy-fuel flame using increased amounts of $\mathrm{CO}_{2}$ dilution to reach distributed reaction. For the first case, lowering the equivalence ratio led to a reduction in the peak sound pressure level around $500 \mathrm{~Hz}$ and a decrease in heat release fluctuations. For all the equivalence ratios, close coupling between acoustic signature and heat release fluctuations existed around $200 \mathrm{~Hz}$. Distributed combustion, achieved at oxygen concentration below 15\%, showed a much lower peak sound pressure levels at the $500 \mathrm{~Hz}$ range with no coupling between heat release fluctuations and acoustic signal, outlining the flame stability at this regime. Also, the noise emission levels were significantly reduced under this mode. For the third regime, increase in $\mathrm{CO}_{2}$ dilution resulted in high heat release fluctuations and an unstable flame which oscillated between two different flame modes, a feature that did not exist in the first two regimes. Further increase in $\mathrm{CO}_{2}$ led to achieving distributed reaction and a much more stable flame as compared to its oscillatory behavior at lower $\mathrm{CO}_{2}$ amounts, along with reduced noise emission levels. This outlines the possibility of achieving distributed combustion in a stable manner via $\mathrm{CO}_{2}$ dilution in oxy-fuel flames.
\end{abstract}

Keywords: Colorless distributed combustion, Oxy-fuel combustion, Flame stability, Heat release fluctuations, Noise emission, Gas turbine combustion.

\footnotetext{
* Corresponding author: Tel.: +1 301405 5276; Fax: +1 3013149477.

E-mail address: akgupta@umd.edu (A. K. Gupta).
} 


\section{Introduction}

The quest for environmentally friendly energy conversion as well as increased awareness of greenhouse gas $\left(\mathrm{CO}_{2}\right)$ emission and its impact on climate change and global warming have motivated energy researchers to look for advanced methods to utilize available fossil fuels. In almost all cases the objectives are minimizing the pollutants emitted during energy conversion and also limit the amounts of carbon dioxide $\left(\mathrm{CO}_{2}\right)$ emitted to the atmosphere. Over the past couple of decades, different research groups have proposed combustion methods that minimize combustion emissions, such as rich-quench-lean burn (RQL) [1-3], flameless oxidation (FLOX) [4,5], moderate or intense low oxygen dilution (MILD) [6], and colorless distributed combustion (CDC) $[7,8]$.

Carbon capture and sequestration has been proposed and demonstrated to mitigate the greenhouse gas emissions so that one can continue using available fossil fuels while mitigating the harmful effect of carbon dioxide emission. To alleviate the process of separating $\mathrm{CO}_{2}$ from the product gases stream (which contains large amounts of nitrogen due to air combustion), oxyfuel combustion has been proposed and demonstrated. The benefit of oxy-fuel combustion is that the product gases are mainly $\mathrm{CO}_{2}$ and water vapor, making the separation process much easier with significant and cost savings and increased plant efficiency. The benefits of oxy-fuel combustion include ease of carbon dioxide separation, and mitigation of thermal and prompt $\mathrm{NO}_{\mathrm{x}}$ formation due to no nitrogen in the oxidizer. It is noteworthy that most of the $\mathrm{NO}_{\mathrm{x}}$ formed in gaseous fuels combustion is from thermal $\mathrm{NO}_{\mathrm{x}}$ route following the Zeldovich mechanism [9].

Dynamic stability of flames, and their response to fluctuations is one of the critical factors in clean combustion. It is critical to ensure that any momentary fluctuation in the inlet flow does not create significant perturbations to the heat release from within the combustor that can feed 
back to the initial fluctuations via dynamic pressure oscillations. Such feedback can create resonance, flame extinction, as well as undesired damage to the combustor body and injectors as well as increased noise emission levels. The dynamic response of flames and flame transfer function (relation between heat release fluctuations and inlet flow fluctuations) have been studied in details to understand the controlling factors behind this behavior for different combustors [1014]. Other researchers focused on the underlying reasons of such instabilities with extension to lab scale flames [15-17] and swirl flames [18-20], offering significant insights on these instabilities and the associated impacts from them.

As the importance of flame instabilities and flame dynamic response is established, this paper focuses on examining a swirl flame burner with special emphasis on its transition to colorless distributed combustion mode using both air combustion and oxy-fuel combustion. Colorless distributed combustion relies on the internal recirculation and entrainment of reactive hot species and product gases from within the combustor, and their fast mixing with the fresh mixture to form a low oxygen concentration and high temperature mixture prior to ignition. The low oxygen concertation slows down the reaction rate such that the reaction covers a larger volume to result in distributed reactions with the same fuel consumption. This low reaction rate is maintained by the high temperature of the oxidizer. Under this conditions, the reaction rate is uniform across the reactor volume to alleviate any hot spots and/or any local stoichiometry variation. CDC investigations have demonstrated significant emissions reduction under different configurations $[7,8,21,22]$ and fuel flexibility $[23,24]$. The required conditions to achieve CDC and the subsequent uniform local equivalence ratio and thermal fields within the reaction zone has been described in the literature; distinguishing distributed combustion from swirl assisted flames under the same flow conditions $[25,26]$. However, to date, there has been no effort to quantify 
any fluctuations in the flame as there were no noticeable instabilities under distributed combustion condition. One of the goals of this paper is to fill this gap.

Though no instabilities have been observed while transitioning to distributed combustion using $\mathrm{N}_{2} / \mathrm{CO}_{2}$ dilution, the same cannot be said for oxy-fuel combustion with $\mathrm{CO}_{2}$ dilution to achieve distributed combustion. This is owing to oxy-fuel combustion characteristics being different than that of air combustion in several aspects. Oxy-fuel combustion is characterized by higher flame speed (up to an order of magnitude larger [27]). In addition, higher adiabatic flames (by $\sim 30 \%$ ) are another aspect of oxy-fuel combustion. These two features dictate that large amounts of exhaust gases are needed (using for example recirculation) to result in decreased flame temperatures, thus preventing excessive heat evolution and to stabilize the flame [27, 28]. Oxy-fuel combustion has been studied in details with focus on furnace applications [29-33]. Some studies have suggested that the flame is difficult to stabilize below $21 \%$ oxygen concentration in oxygen-carbon dioxide mixtures [34-35].

In this paper, the flame acoustic signature and heat release fluctuations are quantified under different conditions representing swirl flames, transition to distributed combustion using $\mathrm{N}_{2} / \mathrm{CO}_{2}$ dilution, and oxy-fuel combustion with increased $\mathrm{CO}_{2}$ dilution. To identify heat release fluctuations, $\mathrm{CH}^{*}$ chemiluminescence diagnostics was used as $\mathrm{CH}^{*}$ has been widely reported to be one of the markers for flame, especially when evaluating flame transfer function [36-39]. As for the acoustic signatures, calibrated microphones were used as described in the next section. Identifying both signals (acoustic and heat release fluctuations) are critical to assess the flame behavior and stability under distributed combustion as well as the possibility of incorporating distributed combustion with oxy-fuel operation. 


\section{Experimental Facility}

The experiments were performed using a swirl burner fueled with methane in three different combinations for oxidants (methane-air, air-methane with $\mathrm{N}_{2} / \mathrm{CO}_{2}$ dilution, and oxygen-methane with $\mathrm{CO}_{2}$ dilution). Details of this swirl burner can be found elsewhere [25]. To simulate product gas entrainment and lower oxygen concentration in the mixture prior to ignition, different amounts of $\mathrm{N}_{2}-\mathrm{CO}_{2}$ mixture were added to the air upstream of the burner. The flow control setup can be found in the literature along with measurement accuracy on data [25]. Nitrogen and carbon dioxide were mixed in a ratio of $90 \% \mathrm{~N}_{2}-10 \% \mathrm{CO}_{2}$ by volume simulating product gases near stoichiometric conditions. Further details on this selection can be found in the literature [25]. The flow field for this swirler has been characterized under both reacting and non-reacting flow relating to the cases studied herein. In these investigations, the mean and fluctuating velocities were obtained along with the reaction zone with focus on fluid mechanics behavior and flame-flow interaction [40-42]

For oxy-fuel experiments, different amounts of carbon dioxide were added that lowered the oxygen concentration, and showed the impact of $\mathrm{CO}_{2}$ dilution on the resulting flame behavior. The flow control setup can be found in the literature along with measurement accuracy for $\mathrm{CO}_{2}$ dilution experiments as well [43]. The injection of carbon dioxide simulates the entrainment of product gases from within the combustor, albeit at lower temperature, in an oxy-fuel combustor.

Acoustic signals were recorded using multiple microphones around the burner with one microphone located farther away from the combustor to obtain the background noise levels. The microphones were positioned along the vertical axis of the combustor. The data reported herein is from the microphone with highest signal which corresponded to the flame region. The microphones were connected to a dedicated highspeed data acquisition system (NI-9324). The 
data acquisition (DAQ) was performed using LABVIEW at a rate of $25 \mathrm{KHz}$ allowing spectral analysis up to $12.5 \mathrm{KHz}$. The microphones were calibrated against a known signal before every experiment. For $\mathrm{CH}^{*}$ chemiluminescence, a photomultiplier tube (PMT, Hamamatsu PMTHC120) was used with a band pass filter centered at 430nm. The PMT was connected to the same DAQ system, operating at the same frequency allowing simultaneous sampling of both acoustic and heat release (via $\mathrm{CH}^{*}$ chemiluminescence) signals. The obtained data were further processed in MATLAB to subtract background noise and obtain the power spectrum of the different signals acquired. For each case, a total of 10 seconds of measurements were recorded (250,000 points) which were then used to obtain the data in frequency domain for further analysis.

For visible fluctuations analysis, a high-speed camera (IDT Redlake Y4) was used with at a frame rate of 120 frames per second. These frames were further analyzed using a Matlab code to determine the visible emission fluctuation frequencies across each pixel of the image. For these evaluations, 2,000 frames were used.

For all the cases, the flames were confined in the quartz tube having an internal diameter of 3 inches and length of 12 inches. Thermocouples were fitted along the reactor walls to confirm the existence of reaction zone at low oxygen concentration as the flame was almost invisible (colorless) with almost no combustion noise.

\section{Experimental Conditions}

The experimental investigations reported here were focused on obtaining the flame acoustic signals and heat release fluctuations from swirl flames using $\mathrm{N}_{2} / \mathrm{CO}_{2}$ dilution; achieving distributed combustion, and oxy-fuel combustion diluted with $\mathrm{CO}_{2}$. Tables 1-3 summarize the 
operating conditions for each of the experimental cases reported here. The fuel flow rate was kept constant for all the experiments to result in a constant thermal load. The lower limit for the oxygen concentration in the oxidizer was determined based on the observed instabilities of the flame and flame blowout when the oxygen was further reduced below these values. Higher oxygen concentration (higher than 40\%), in the oxy-fuel experiments, were not examined as the flame shifted towards the swirler due to the higher flame speed, overheating the swirler body. The heat load was kept constant at $3.25 \mathrm{KW}$ to give a heat (thermal) release intensity of 2.4 $\mathrm{MW} / \mathrm{m}^{3}$-atm. The experiments were performed at room temperature and pressure with no preheats to any of the gases. The percentage values mentioned here are based on volumetric basis. Isothermal flow acoustic signal was also recorded for these cases, with the resulting signal being one or two orders of magnitude lower than the reacting flow cases. This limited their use in the analysis. Reynolds number reported in tables 1-3 are calculated at the inlet of the combustion volume, considering the different properties of the inlet mixture at each case. Reynolds number is used herein to offer a way to compare the inlet conditions for each of the cases investigated.

For each of experimental data acquisition, points from table 1 were always acquired along with the desired data from tables 2 and 3. The data from table 1 were used as a baseline case which were then compared with data from different experimental runs, accounting for any runto-run fluctuations or variations of the surroundings. Consequently, comparing behavior of cases 6-11 and 12-18 could be performed easily as both related to cases $1-5$ performed on that specific run.

\title{
4. Results and Discussion
}

\author{
4.1 Global Flame Shape
}


The flame shapes for each of the experimental cases are shown herein in comparison to the base case (at equivalence ratio, phi=0.9 using normal air with $\mathrm{O}_{2}=21 \%$ ). These global images as well as $\mathrm{OH}^{*}$ chemiluminescence emissions have been discussed in details in our previous publications $[26,43]$. Their purpose herein is to give an idea about the flame shape at different conditions prior to discussing the flame frequency response in the following sections.

\subsection{Methane Air Flame}

The first set of experiments focused on establishing the response of a methane air swirling flame, which will be used here as a baseline case for comparison. Figure 4 shows the acoustic response of the flame in frequency domain for the different equivalence ratios examined, expressed in arbitrary units [A.U.].

Three peaks can be seen for the different equivalence ratios examined. The largest peak is at $500 \mathrm{~Hz}$, which is consistent with literature on combustion noise and precessing vortex core on the swirl flames frequency response $[44,45]$. As the equivalence ratio was decreased, the amplitude at those frequencies decreased significantly (at phi $=0.6$, the amplitude was $50 \%$ of that at phi=0.9). Another peak was observed around $200 \mathrm{~Hz}$ (shifting between 180 and $240 \mathrm{~Hz}$ depending on the equivalence ratio), and a third peak around $1400 \mathrm{~Hz}$. The $1400 \mathrm{~Hz}$ peak can be related to the burner configuration, while the $\sim 200 \mathrm{~Hz}$ peaks can be related to heat release fluctuations and thermo-acoustic coupling [46]. As the heat release fluctuates, the density changes leading to pressure oscillations. These pressure oscillations result in an acoustic signal, outlining the thermos-acoustic coupling. This was validated by analyzing the heat release fluctuations in frequency domain as shown in Fig. 5. For each equivalence ratio, the low frequency acoustic 
signal (in the $200 \mathrm{~Hz}$ region corresponded with the heat release fluctuation signal at the same exact frequency as shown from comparing Figs. 4 and 5.

For equivalence ratio of 0.9 , this behavior was seen in multiple peaks that presented in both the acoustic signal and the heat release fluctuations signal specifically at frequencies of $172 \mathrm{~Hz}$ and $230 \mathrm{~Hz}$. For the lowest equivalence ratio, a heat release peak was seen at low frequencies $(\sim 25 \mathrm{~Hz})$, yet a common peak between heat release fluctuations and sound pressure level was seen at $184 \mathrm{~Hz}$, see Fig. 6 . It is noteworthy that the low frequency peak $(\sim 25 \mathrm{~Hz})$ was only seen at equivalence ratio of 0.55 near the flammability limit. Below this equivalance ratio, high instabilites were encountered, with flame blowout prior to significant data collection.

\subsection{Oxygen Concentration Reduction using $\mathrm{N}_{2}-\mathrm{CO}_{2}$ Mixture}

With the performance of the swirl flame established in terms of acoustic signature and heat release fluctuations, experiments were performed with different amounts of $\mathrm{N}_{2} / \mathrm{CO}_{2}$ addition to reduce the oxygen concentration in the reactants while maintaining the same equivalence ratio and heat load. As the oxygen concentration decreased below $\sim 15 \%$, distributed combustion was established in this combustor as discussed in previous publications. Figure 7 shows the sound pressure level for these cases with oxygen concentration varying from $21 \%$ down to $13.8 \%$.

As the oxygen concentration was reduced, one can see that the peak at $500 \mathrm{~Hz}$ was significantly reduced (at $13.8 \%$ oxygen concentration, the peak amplitude was $18 \%$ of that at $21 \%)$. In addition, the frequencies at the $200 \mathrm{~Hz}$ range were significantly reduced at oxygen concentration of $15.58 \%$ and below until it disappeared at $\mathrm{O}_{2}=13.8 \%$. The heat release fluctuations are shown in Fig. 8. As the oxygen concentration was reduced, an increase in the low frequency heat release fluctuations were observed $(<25 \mathrm{~Hz})$, specifically for the $17.88 \%$ and 
$16.65 \%$ oxygen cases. Further reduction in oxygen concentration reduced these peaks as seen in $15.58 \%, 14.64 \%$ and $13.8 \%$ concentrations cases.

Figure 9 shows three specific cases representing oxygen concertation of $21 \%$ (swirl flame) and concentrations of $14.64 \%$ and $13.8 \%$ (where distributed combustion was observed). The sound pressure level signals were significantly reduced with oxygen concentration reduction as shown previously. In addition, the heat release fluctuation shifted to a lower frequency. Note that the total fluctuations were also significantly reduced.

If one uses the area under the curve to express the total heat release fluctuations at different frequencies, the data can be plotted for heat release fluctuations reduction vs. Reynolds number. The results are shown in Fig. 10. Reynolds number was chosen so that different cases of equivalence ratio and oxygen concentration reduction can compared based on similar Reynolds number.

The baseline was case 1 at phi $=0.9$, and Reynolds number $(\mathrm{Re})$ of $\sim 4450$. Decreasing the equivalence ratio (and increasing the Reynolds number) led to a decrease in heat release fluctuation up to $\sim 50 \%$ at phi=0.6 (blue dots in Fig. 10). On the other hand, adding $\mathrm{N}_{2} / \mathrm{CO}_{2}$ to decrease $\mathrm{O}_{2}$ concentration lead to an increase in heat release fluctuations (for $\mathrm{O}_{2}=17.78 \%$, $\operatorname{Re} \sim 5240$ ), followed by a decrease of heat release fluctuations for further reduction of oxygen concentration (see red dots in Fig. 10). At oxygen concentration of $13.8 \%$, the reduction of heat release fluctuations was about $50 \%$ as well.

The amplitude of fluctuations was not the only factor to consider. Another factor was to see whether the acoustic signal and the heat release fluctuations were in phase or not. Both signals were examined in time domain and frequency domain. Analysis revealed that there was no correlation between both signals in time domain, indicating that they were out of phase. On the 
frequency domain, strong correlation was found at $200 \mathrm{~Hz}$ range wherein both the heat release fluctuations and sound pressure level signals demonstrated significant peaks. Figure 11 shows the obtained correlation between the data in time domain, which was then converted into frequency domain (two left plots), and the correlation between the data in frequency domain (two right plots). The lack of peaks in the time domain data (left figures) indicates that the signals were out of phase. The high peak in the frequency domain data $\left(\mathrm{O}_{2}=21 \%\right.$, right figures $)$ indicate that the heat release fluctuations and sound pressure level indeed have common frequencies as outlined before. The lack of peaks in the frequency domain data at $\mathrm{O}_{2}=13.8 \%$ was related to the low sound pressure level for this flame as well as the disappearance of the $200 \mathrm{~Hz}$ heat release peak as discussed before.

\subsection{Oxygen-Fuel Combustion with $\mathrm{CO}_{2}$}

Experiments were also performed using oxygen diluted with carbon dioxide as the oxidizer with focus on favorable oxy-fuel combustion conditions. Figure 12 shows the sound pressure level for these carbon dioxide diluted cases. The first thing to notice was the shift in the main peak frequency $(\sim 500 \mathrm{~Hz}$ as shown in previous cases) to $\sim 415 \mathrm{~Hz}$. This shift can be related to the

change in average mixture density (from $\sim 1.15 \mathrm{Kg} / \mathrm{m}^{3}$ for air and $\mathrm{N}_{2} / \mathrm{CO}_{2}$ dilution to $\sim 1.6 \mathrm{~kg} / \mathrm{m}^{3}$ for $\mathrm{CO}_{2}$ dilution). Similar to $\mathrm{N}_{2} / \mathrm{CO}_{2}$ dilution, the peaks at $\sim 200 \mathrm{~Hz}$ disappeared upon decrease in $\mathrm{O}_{2}$ concentration.

The peak at $200 \mathrm{~Hz}$ in heat release fluctuations signal indeed disappeared with decrease in oxygen concentration, with the fluctuations being at lower frequencies, see Fig. 13. However, unlike previous cases, the amplitude of the peaks significantly increased rather than decreased in the low frequency range as seen before. 
Figure 14 shows the peak amplitude for the different oxygen concentrations with $\mathrm{CO}_{2}$ dilution, normalized by the peak recorded for air-methane combustion case at equivalence ratio of 0.9 (case 1). The data for different equivalence ratio and $\mathrm{N}_{2} / \mathrm{CO}_{2}$ dilution is shown on the same plot with Reynolds number as X-axis for easier comparison (as Reynolds number increased, equivalence ratio decreased (blue dots), and oxygen concentration decreased due to $\mathrm{N}_{2} / \mathrm{CO}_{2}$ addition (red dots) or $\mathrm{CO}_{2}$ increased in oxy-flame dilution (green dots)). From the figure, one can see that for different equivalence ratios and $\mathrm{N}_{2}-\mathrm{CO}_{2}$ dilution, peak amplitude decreased as compared to the baseline case. On the other hand, for $\mathrm{O}_{2}-\mathrm{CO}_{2}$ flame, upon $\mathrm{CO}_{2}$ addition, the peak increased by 8.5 folds the baseline case then decreased again to about 2.5 folds the baseline case.

To further investigate this increase in heat release peak, a high-speed camera was used to capture this oscillation. The frequency obtained from the heat release fluctuations was about $11 \mathrm{~Hz}$. Consequently, the camera was operated at $120 \mathrm{~Hz}$ to capture any fluctuations and insure there was enough exposure time for adequate signal. The highspeed images showed significant flame oscillation where the flame changed its shape from a traditional V-shape (characteristic of swirl flames) to a lifted flame covering a larger volume. This oscillation was not seen in previous cases of lower equivalence ratio or lower oxygen concentration via $\mathrm{N}_{2} / \mathrm{CO}_{2}$ addition. Figure 15 shows 20 successive frames with time differences of $8.33 \mathrm{~ms}$, showing oscillatory behavior of the flame.

Analysis of the obtained frames (2000 frames) showed that the flame oscillated at a frequency of $11 \mathrm{~Hz}$. This flame oscillation was obtained by performing fast Fourier transformation on each pixel on the frame across the obtained 2000 frames using a Matlab code. This result was verified 
by running the camera at different frequencies of 100 and $200 \mathrm{~Hz}$, for which the obtained oscillation frequency was $11 \mathrm{~Hz}$. Note that this oscillation could also be observed by naked eyes.

This oscillatory behavior was noticed for oxygen concentration between $30 \%$ to $25 \%$ with the data shown in Fig 15 for concentration of $27.5 \%$, where these oscillations were at their maximum. Similar behavior has been reported previously in the literature [47-51]. Arndt et al. examined a swirl combustor where, under certain conditions, the flame oscillated between two states, similar to what was shown here with similar frequency [50]. In another investigation, a stable flame was established that transitioned between those two states since the focus was to outline the underlying mechanism [51]. They suggested that increased inflow and local turbulence lead to local extinction at flame root and, due to the resulting favorable density profile, a precessing vortex core $(\mathrm{PVC})$ initiated. This favorable profile remained for short time and thus this PVC was suppressed and the flame returned to V-shape [51].

However, these research findings were performed on methane air swirl flames or with steam addition, which do not address $\mathrm{N}_{2} / \mathrm{CO}_{2}$ addition or oxy-fuel combustion with $\mathrm{CO}_{2}$ dilution discussed here. Generally speaking, the $\mathrm{O}_{2}-\mathrm{CO}_{2}$ flames had much higher temperatures (adiabatic flame temperatures ranged between $2363 \mathrm{~K}$ and $1780 \mathrm{~K}$ ) as compared to methane air flame (2130K-1575K) or that with $\mathrm{N}_{2}-\mathrm{CO}_{2}$ dilution $(2130 \mathrm{~K}$ to $1628 \mathrm{~K})$. For the oscillation cases, the adiabatic flame temperatures at the oscillatory flames were $2088 \mathrm{~K}$ to $1880 \mathrm{~K}\left(30 \%-25 \% \mathrm{O}_{2}\right)$. On the other hand, flame shape change for $\mathrm{N}_{2} / \mathrm{CO}_{2}$ dilution was found to be at a temperature of $\sim 1700 \mathrm{~K}$. This much higher temperature range combined with higher density found in $\mathrm{O}_{2}-\mathrm{CO}_{2}$ flame, $1.6 \mathrm{~kg} / \mathrm{m}^{3}$ vs $1.15 \mathrm{~kg} / \mathrm{m}^{3}$ as discussed earlier, was seen to be the factor behind this oscillatory behavior, which was not observed in previous experiments using methane air or $\mathrm{N}_{2} / \mathrm{CO}_{2}$ dilution which has lower temperature and overall density. Note that for these different 
transition cases, Reynolds number ranged from 5200-6200 (oscillatory cases of the $\mathrm{O}_{2}-\mathrm{CO}_{2}$ experiments) and 5600-6400 (transition to distributed combustion for Air- $\mathrm{N}_{2}-\mathrm{CO}_{2}$ dilution), indicating similar isothermal flowfield features.

Once the oxygen concentration dropped below 25\%, this oscillatory behavior was significantly decreased to result in a more stable flame. This can be seen through the total heat fluctuations (calculated using the area under the heat release fluctuation curve), see green dots on Fig. 16. The point at $\mathrm{Re}=3780, \mathrm{O}_{2}=40 \%$ demonstrated high heat release fluctuations, however, this point had a different flame shape as shown in Fig. 3 with increased tendency for the flame to flashback and settle in the swirler resulting in this high fluctuation. Starting from $\mathrm{O}_{2}=35 \%$, $\mathrm{Re}=4350$, as the amounts of $\mathrm{CO}_{2}$ increased, the total heat release fluctuation reduction increased as a negative value (i.e. the fluctuations increased) and reached a maximum at $\mathrm{O}_{2} \%$ of $27.5 \%$ ( $\mathrm{Re}$ 5640). Further reduction in $\mathrm{O}_{2}$ led to more stability and heat release fluctuation reduction. In general, the $\mathrm{O}_{2}-\mathrm{CO}_{2}$ flame had higher fluctuations compared to different equivalence ratio cases (blue dots) or $\mathrm{N}_{2}-\mathrm{CO}_{2}$ dilution cases (red dots), also shown on Fig. 16.

On the other hand, the $\mathrm{O}_{2}-\mathrm{CO}_{2}$ flame resulted in much lower noise emission. Figure 17 shows the recorded sound pressure level in A-weighted decibel (dBA). From the figure, it can be seen that lowering oxygen concentration and transition to distributed combustion through $\mathrm{N}_{2} / \mathrm{CO}_{2}$ dilution resulted in significant noise reduction (red dots) as compared to decrease in equivalence ratio (blue dots). Though increasing $\mathrm{CO}_{2}$ and diluting $\mathrm{O}_{2}$ in oxy-fuel flame led to increase in heat release fluctuations, the sound pressure level consistently decreased with increased dilution to result in the lowest sound signature as compared to other cases (green dots), to result in 25dBA reduction in noise as compared to the baseline case. Increase in the equivalence ratio resulted in 
6.5 dBA reduction (blue dots), while $\mathrm{N}_{2} / \mathrm{CO}_{2}$ addition achieved distributed combustion that resulted in $17.3 \mathrm{dBA}$ noise reduction (red dots).

Comparing both the sound pressure level signal and heat release fluctuations signal, no correlation between the data in time domain was found, indicating that these variations are out of phase, as shown in previous cases (Fig. 11). Data suggest that distributed combustion with oxyfuel operation can be achieved via $\mathrm{CO}_{2}$ dilution, provided that the dilution was significant enough to avoid the oscillatory regime encountered here between $30 \%$ and $25 \% \quad \mathrm{O}_{2}$ concentration.

\section{Conclusions}

The acoustic emission as well as heat release fluctuations were recorded from a swirl combustor operation under normal conditions, distributed combustion, and oxy-fuel combustion. Results showed that, lowering equivalence ratio reduced both the acoustic signal and heat release fluctuations, however, coupling between both existed, specifically near the $200 \mathrm{~Hz}$ range.

As one transitions to distributed combustion, with oxygen concentration below $15 \%$, the coupling at $200 \mathrm{~Hz}$ disappeared with a much lower acoustic signal and heat release fluctuations, outlining the benefits of operating in a distributed combustion regime in terms of increased stability (50\% reduction in heat release fluctuations) and noise reduction (17 $\mathrm{dBA}$ reduction) with no correlation between the heat release fluctuations and the sound pressure levels.

For oxy-fuel combustion, increase in $\mathrm{CO}_{2}$ dilution led to disappearance of the acoustic-heat release fluctuations coupling at the $200 \mathrm{~Hz}$ range. However, heat release fluctuations were significantly increased in the low frequency range $(<25 \mathrm{~Hz})$, a feature that was not demonstrated in earlier cases. These fluctuations reached a maximum at about $27.5 \% \quad \mathrm{O}_{2}$ in $\mathrm{O}_{2}-\mathrm{CO}_{2}$ mixture. 
This increase in heat fluctuation resulted from the flame transition between two modes as shown through high speed imaging. This transition between these two modes was fostered by the higher temperatures in oxy-fuel combustion along with the heavier density as compared to air flames. Further increase in $\mathrm{CO}_{2}$ dilution led to reduction in heat release fluctuations reaching a minimum at $23 \%$. This indicates the possibility of having oxy-fuel flame operating in distributed combustion mode with minimal instability and much reduced sound pressure levels (27 dBA reduction).

\section{Acknowledgments}

This research was supported by the Office of Naval Research (ONR) and is gratefully acknowledged.

\section{References}

[1] Tacina RR. Low NOx Potential of Gas Turbine Engines. NASA Technical Memorandum, $28^{\text {th }}$ AIAA Aerospace Sciences Meeting, Reno, Nevada, January 8-11, 1990. Paper \# AIAA-900550

[2] Rizk NK, Mongia HC. Low NOx Rich-Lean Combustion Concept Application. $27^{\text {th }}$ AIAA Joint Propulsion Conference, Sacramento, California, June 24-26, 1991. Paper \# AIAA91-1962

[3] Feitelberg AS, Lacey MA. The GE Rich-Quench-Lean Gas Turbine Combustion. J. Eng. Gas Turbines Power, 1998;120(3):502-8

[4] Wunning JA and Wunning JG. Flameless Oxidation to Reduce Thermal NO Formation. Progr. In Energy and Combustion Science, 1997;23:81-94. 
[5] Lammel O, Schutz H, Schmitz G, Luckerath R, Stohr M, Noll B, Aigner M, Hase M, Krebs W. FLOX Combustion at High Power Density and High Flame Temperature. J. Eng. Gas Turb. Power, 2010;132(12):121503

[6] Cavaliere A, de Joannon, M. MILD Combustion, Progress in Energy and Combustion Science, 2004;30(4):329-66

[7] Arghode VK, and Gupta AK. Effect of Flowfield for Colorless Distributed Combustion (CDC) for Gas Turbine Combustion. Applied Energy, 2010;78:1631-40.

[8] Khalil AEE, and Gupta AK. Swirling Distributed Combustion For Clean Energy Conversion In Gas Turbine Applications. Applied Energy, 2011;88:3685-93.

[9] Correa SM. A Review of NOx Formation under Gas-Turbine Combustion Conditions. Combustion Science and Technology 1992;87:329-62.

[10] Zinn BT and Lieuwen TC. Combustion Instabilities: Basic Concepts. Combustion Instabilities in Gas Turbine Engines: Operational Experience, Fundamental Mechanisms, and Modeling, Progress in Astronautics and Aeronautics, pp. 3-26.

[11] Mongia HC, Held TJ, Hsaio GC, Pandalai RP. Incorporation of Combustion Instability Issues Into Design Process: Ge Aeroderivative And Aero Engines Experience. Combustion Instabilities in Gas Turbine Engines: Operational Experience, Fundamental Mechanisms, and Modeling, Progress in Astronautics and Aeronautics, pp. 43-63.

[12] Scarinci T. Combustion Instability and Its Passive Control: Rolls-Royce Aeroderivative Engine Experience. Combustion Instabilities in Gas Turbine Engines: Operational Experience, Fundamental Mechanisms, and Modeling, Progress in Astronautics and Aeronautics, pp. 65-88.

[13] Krebs W, Bethke S, Lepers J, Flohr P, Prade B, Johnson C, Sattinger S. Thermoacoustic Design Tools and Passive Control: Siemens Power Generation Approaches. Combustion 
Instabilities in Gas Turbine Engines: Operational Experience, Fundamental Mechanisms, and Modeling, Progress in Astronautics and Aeronautics, pp. 89-112.

[14] Cohen JM, Proscia W, Delaat J. Characterization And Control Of Aeroengine Combustion Instability: Pratt \& Whitney And Nasa Experience. Combustion Instabilities in Gas Turbine Engines: Operational Experience, Fundamental Mechanisms, and Modeling, Progress in Astronautics and Aeronautics, pp. 113-45.

[15] Dowling AP, Mahmoudi Y. Combustion Nosie. Proc. Combust. Inst. 2015;35:65-100

[16] Dowling AP, Stow AR. Acoustic Analysis of Gas Turbine Combustors. J. Prop. \& Power $2003 ; 19(5): 751-64$

[17] Dowling AP, A Kinematic Model of Ducted Flame. J. Fluid Mech., 1999;394:51-72

[18] Huang Y, Yang V. Dynamics and Stability of Lean-Premixed Swirl-Stabilized Combustion. Prog. Energy Combust. Sci., 2009;35:293-364

[19] Kang DM, Culick FEC, Ratner A. Combustion Dynamics of a Low-Swirl Combustor. Combust. And Flame, 2007;151:412-25

[20] Syred N. A Review of Oscillation Mechanisms and the Role of the Precessing Vortex Core (PVC) in Swirl Combustion Systems. Prog. Energy Combust. Sci., 2006;32:93-161

[21] Khalil AEE, Gupta AK, Bryden MK, Lee SC. Mixture Preparation Effects on Distributed Combustion for Gas Turbine Applications. J. Energy Resour. Technol., 2012;134(3):032201.

[22] Khalil AEE, Arghode, VK, Gupta, AK. Novel Mixing for Ultra-High Thermal Intensity Distributed Combustor. J. Applied Energy, 2013;105:327-334.

[23] Khalil AEE, and Gupta AK. Fuel Flexible Distributed Combustion with swirl for Gas Turbine Applications. Applied Energy, 2013;109:267-74 
[24] Khalil AEE, and Gupta AK. Clean Combustion in Gas Turbine Engines Using Butyl Nonanoate Biofuel. Fuel, 2014;116:522-528

[25] Khalil AEE, and Gupta AK. Internal Entrainment Effects on High Intensity Distributed Combustion Using Non-Intrusive Diagnostics. Applied Energy, 2015;160:467-476

[26] Khalil AEE, and Gupta AK. Thermal Field Investigation under Distributed Combustion Conditions. Applied Energy, 2015;160:477-488

[27] Shi B, Hu J, Ishizuka S. Carbon Dioxide Diluted Methane/Oxygen Combustion in a Rapidly Mixed Tubular Flame Burner. Combustion and Flame, 2015;162:420-430

[28] Galmiche B, Halter F, Foucher F, Dagaut P. Effects of Dilution on Laminar Burning Velocity of Premixed Methane/Air Flames. Energy \& Fuels, 2011;25:948-954

[29] Heil P, Toporov D, Forster M, Kneer R. Experimental Investigation on the Effect of $\mathrm{O}_{2}$ and $\mathrm{CO}_{2}$ on Burning Rates during Oxyfuel Combustion of Methane. Proc. Of Combustion Institute, 2011;33:3407-3413

[30] Czakiert T, Sztekler K, Karski S, Markiewicz D, Nowak W. Oxy-fuel Circulating Fluidized Bed Combustion in a Small Pilot-scale Test Rig. Fuel Processing Technology, 2010;91:1617-1623.

[31] Duan L, Sun H, Zhao C, Zhou W, Chen X. Coal Combustion Characteristics on an Oxyfuel Circulating Fluidized Bed Combustor with Warm Flue Gas Recycle. Fuel, 2014;127:47-51

[32] Hecht E, Shaddix C, Geier M, Molina A, Haynes B. Effect of $\mathrm{CO}_{2}$ and Steam Gasification Reactions on the Oxy-combustion of Pulverized Coal Char. Combustion and Flame, $2012 ; 159: 3437-3447$

[33] Li P, Dally B, Mi J, Wang F. MILD Oxy-combustion of Gaseous Fuels in a Laboratoryscale Furnace. Combustion and Flame, 2013;160:933-946 
[34] Nemitallah M, Habib M. Experimental and Numerical Investigations of an Atmospheric Diffusion Oxy-combustion Flame in a Gas Turbine Model Combustion. Applied Energy, $2013 ; 111: 401-415$

[35] Williams T, Shaddix C, Schefer R. Effect of Syngas Composition and $\mathrm{CO}_{2}$-Diluted Oxygen on Performance of a Premixed Swirl-Stabilized Combustor. Combustion Science and Technology, 2007;180(1):64-88

[36] Docquier N, Candel S. Combustion Control and Sensors: A Review. Prog, Energy Combust. Sci., 2002;28(2):107-50

[37] McManus KR, Vandsburger U, Bowman CT. Combustor Performance Enhancement Through Direct Shear Layer Excitation. Combustion and Flame, 1990;82(1):75-92

[38] Lieuwen T, Neumeier Y. Nonlinear Pressure-Heat Release Transfer Function Measurements in a Premixed Combustor. Proc. Combust. Inst., 2002;29:99-105

[39] Bellows BD, Bobba MK, Seitzman JM, Lieuwen T. Nonlinear Flame Transfer Function Characteristics in a Swirl Stabilized Combustor. J. Eng. Gas Turbines Power, 2007;129:954-61

[40] Khalil AEE, and Gupta AK. On the Flame-Flow interaction under Distributed Combustion Conditions. Fuel, 182, pp.17-26

[41] Khalil AEE, and Gupta AK. Impact of Confinement on Flowfield of Swirl Flow Burners. Fuel, 184, 1-9

[42] Khalil AEE, and Gupta AK. Towards Colorless Distributed Combustion Regime. Fuel, $195,113-122$

[43] Khalil AEE, and Gupta AK. The Role of $\mathrm{CO}_{2}$ on Oxy-Colorless Distributed Combustion. Applied Energy, 188, pp. 466-474 
[44] Durox D, Moeck JP, Bourgouin JF, Morenton P, Viallon M, Schuller T, Candel S. Flame Dynamics of a Variable Swirl Number System and Instability Control. Combustion and Flame, 2013;160:1729-42

[45] Steinberg AM, Boxx I, Stohr M, Carter CD, Meier W. Flow-Flame Interactions Causing Acoustically Coupled Heat Release Fluctuations in a Thermo-Acoustically Unstable Gas Turbine Model Combustor. Combustion and Flame, 2010;157:2250-66

[46] Boxx I, Stohr M, Carter C, Meier W. Temporally Resolved Planar Measurements of transient phenomena in a partially pre-mixed swirl flame in a gas turbine model combustor. Combustion and Flame, 2015;157:1510-25

[47] Guiberti TF, Durox D, Scouflaire P, Schuller T. Impact of Heat Loss and Hydrogen Enrichment on the Shape of Confined Swirling Flames. Proc. Combust. Inst., 2015;35:1385-92

[48] Hermeth S, Staffelbach G, Gicquel LYM, Anisimov V, Cirigliano C, Poinsot T. Bistable Swirled Flames and Influence on Flame Transfer Functions. Combustion and Flame, 2014;161:184-96

[49] Terhaar S, Oberleithner K, Paschereit CO. Impact of Steam-Dilution on the Flame Shape and Coherent Structures in Swirl Stabilized Combustors. Combust. Sci. Technol., 2014;186:889911.

[50] Arndt C M, Steinberg A M, Boxx I G, Meier W, Carter C D, and Aigner M. Flow-Field and Flame Dynamics of a Gas Turbine Model Combustor During Transition Between ThermoAcoustically Stable und Unstable States. Proc. ASME Turbo Expo, 2010, GT2010-22830

[51] Oberleithner K, Stöhr M, Im S H, Arndt C M, and Steinberg A M. Formation and FlameInduced Suppression of the Precessing Vortex Core in a Swirl Combustor: Experiments and Linear Stability Analysis. Combustion and Flame, 2015;162:3100-3114 


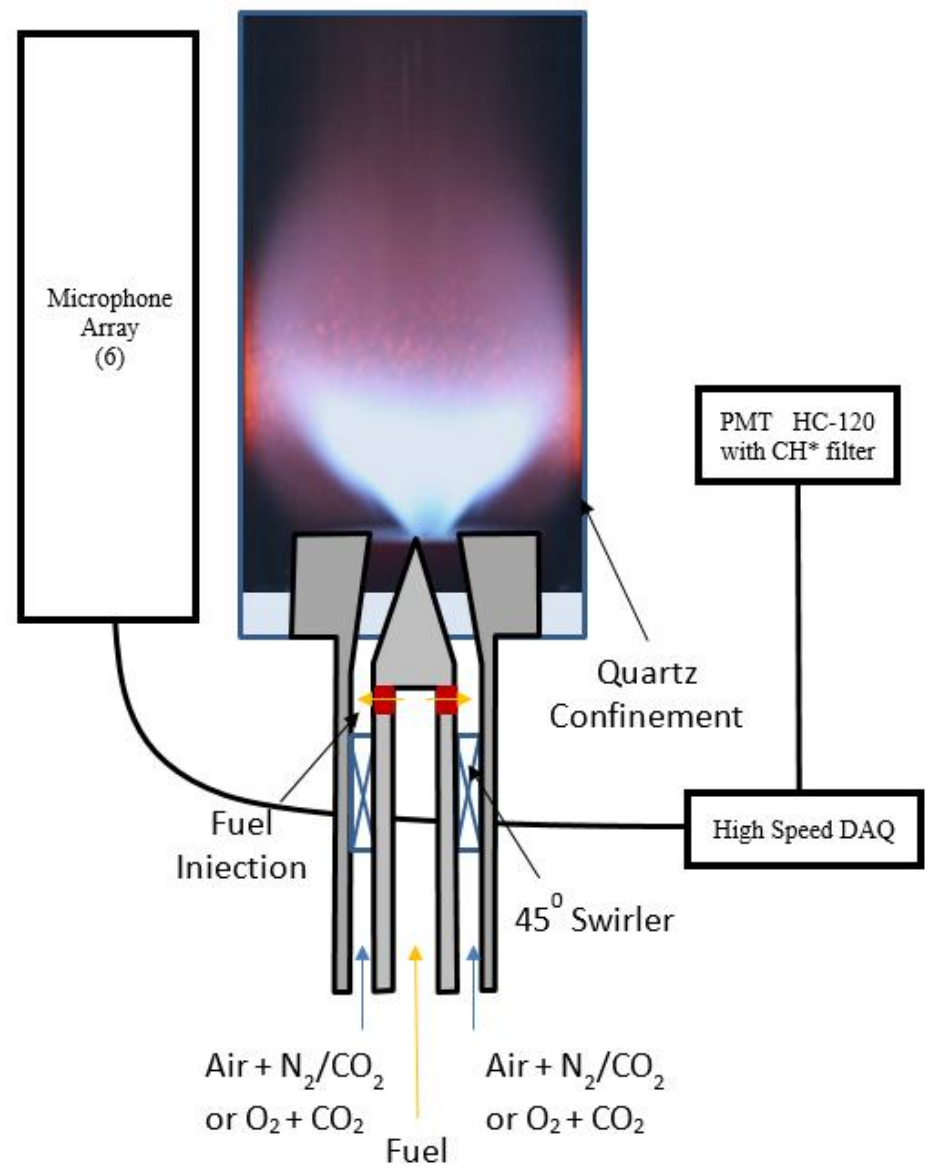

Figure 1. Schematic of the experimental test rig 


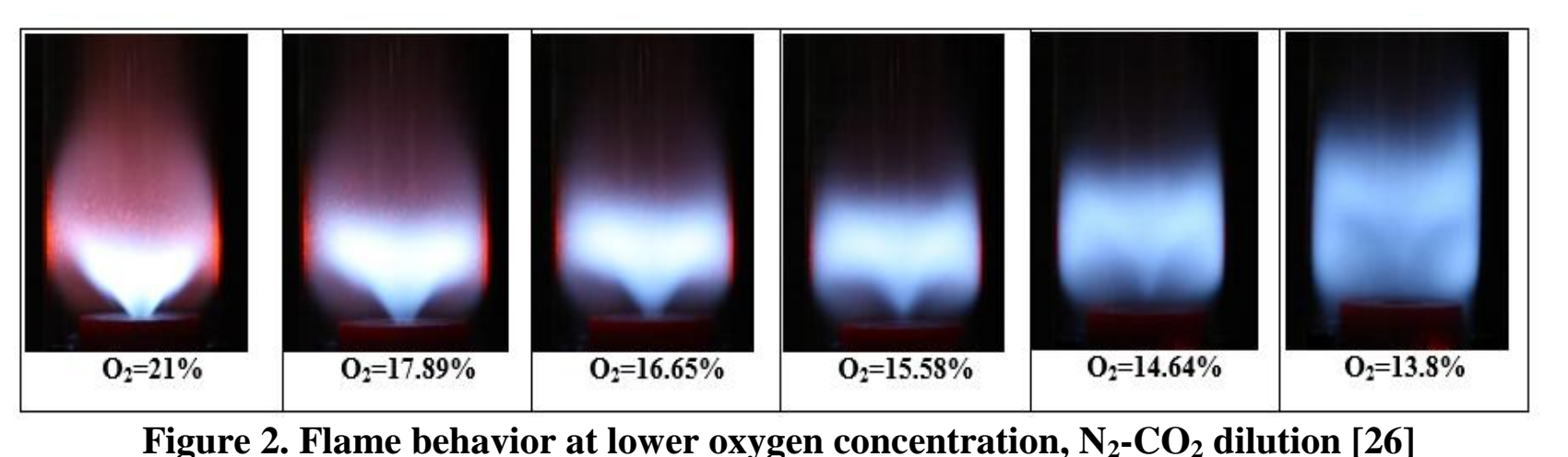

Figure 2. Flame behavior at lower oxygen concentration, $\mathrm{N}_{2}-\mathrm{CO}_{2}$ dilution [26]

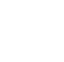
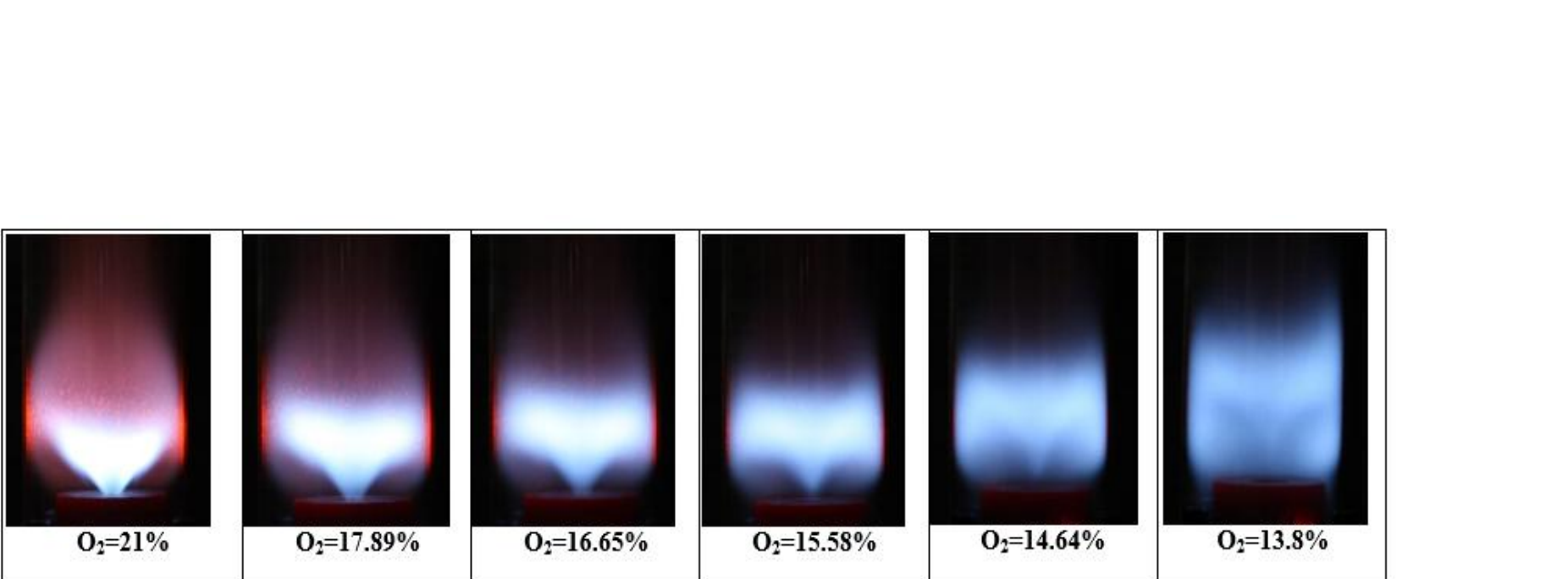

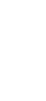

. 


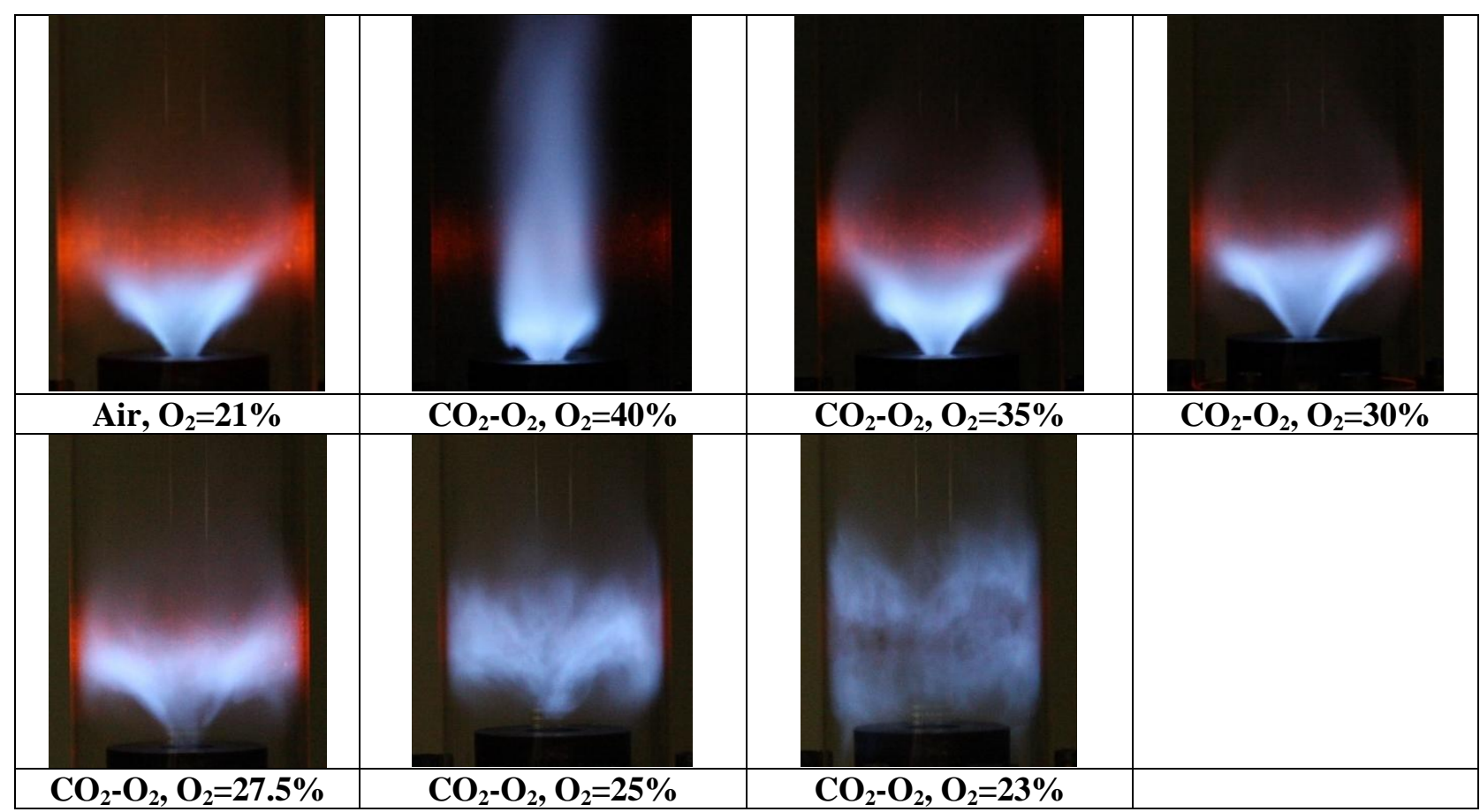

Figure 3. Flame behavior at lower oxygen concentration, $\mathrm{CO}_{2}$ dilution for oxy-fuel combustion [43] 


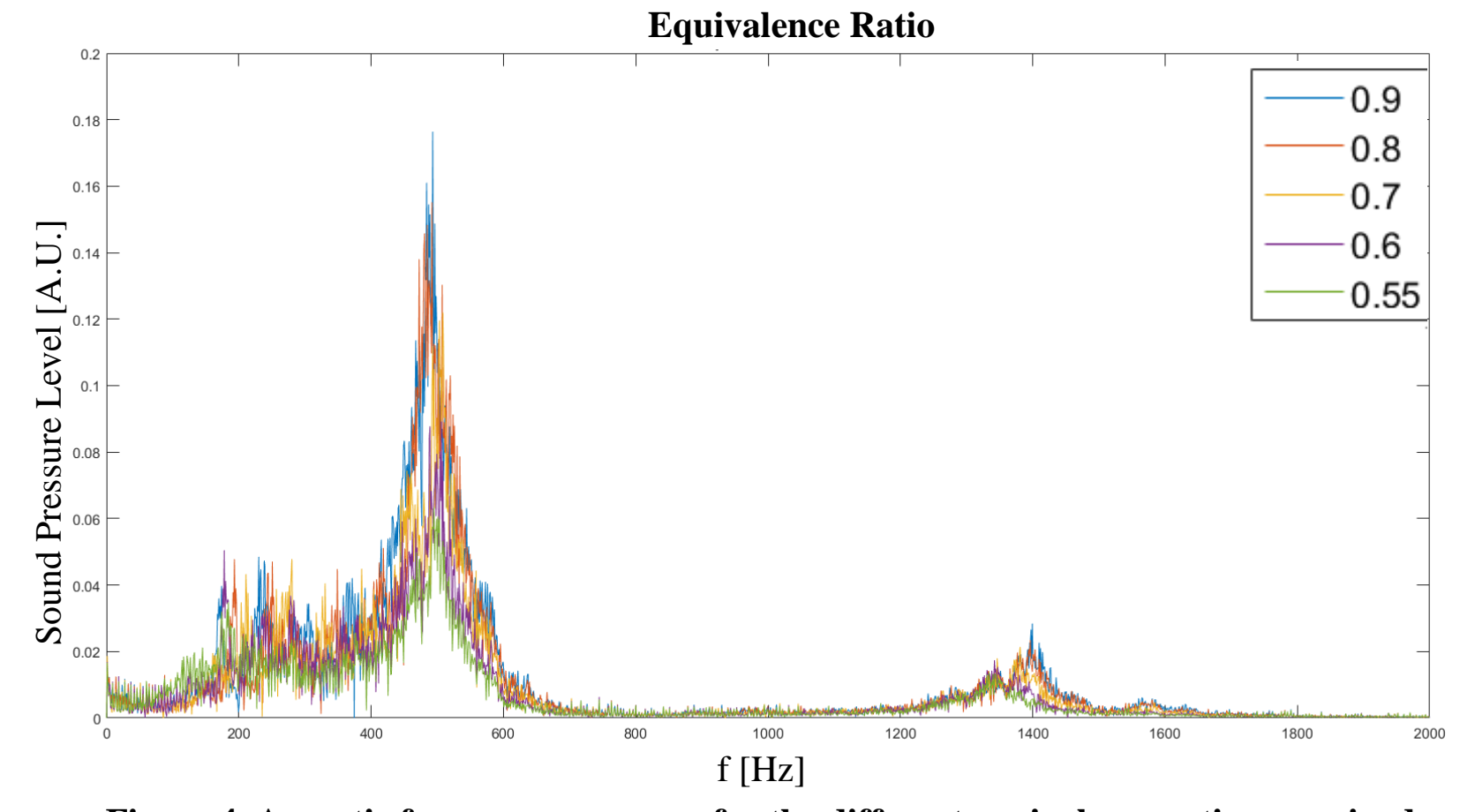

Figure 4. Acoustic frequency response for the different equivalence ratios examined

Equivalence Ratio 

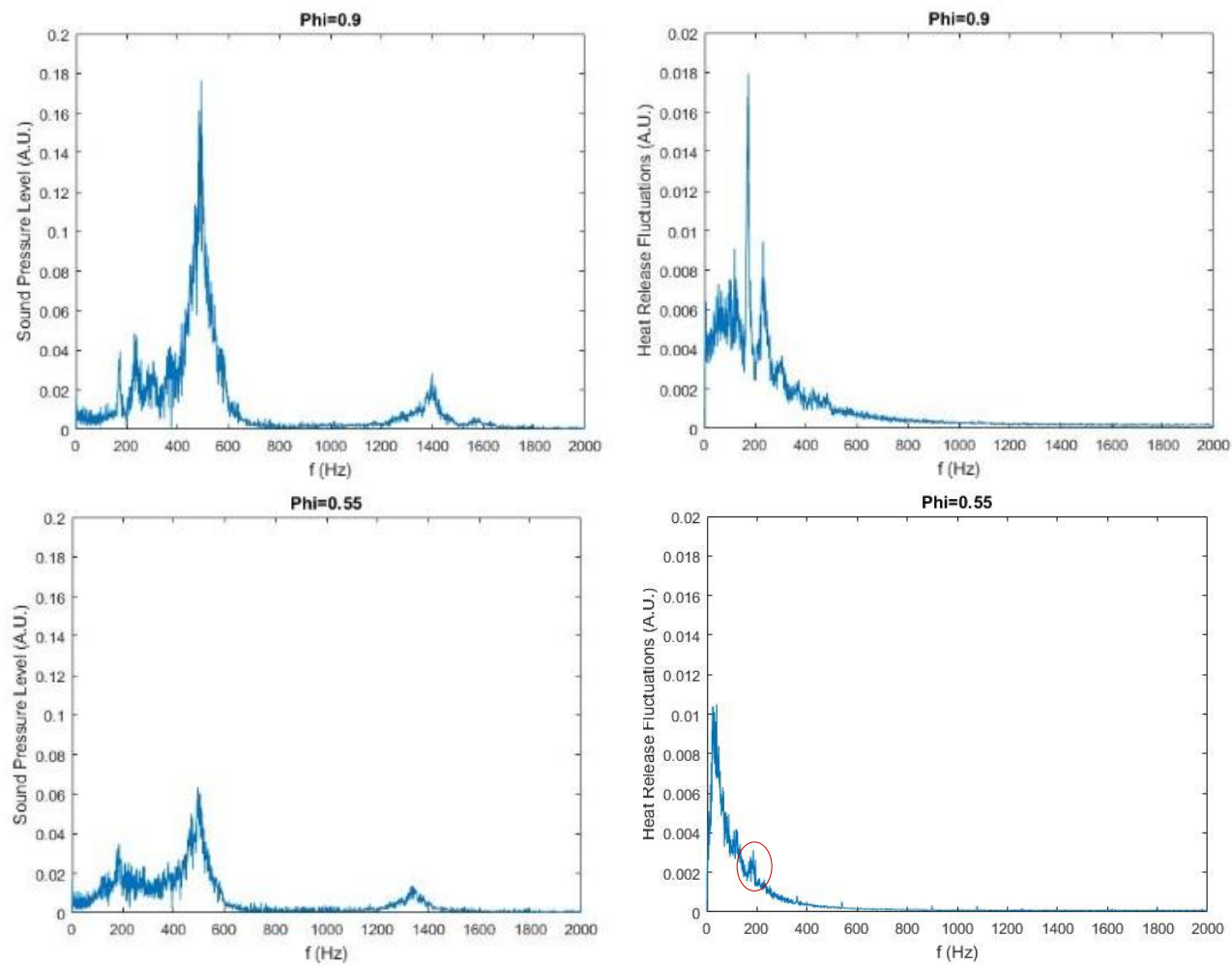

Figure 6. CH* fluctuations (left) and Acoustic signal (right) for phi=0.9 (top) and 0.55 (bottom) 
Figure 7

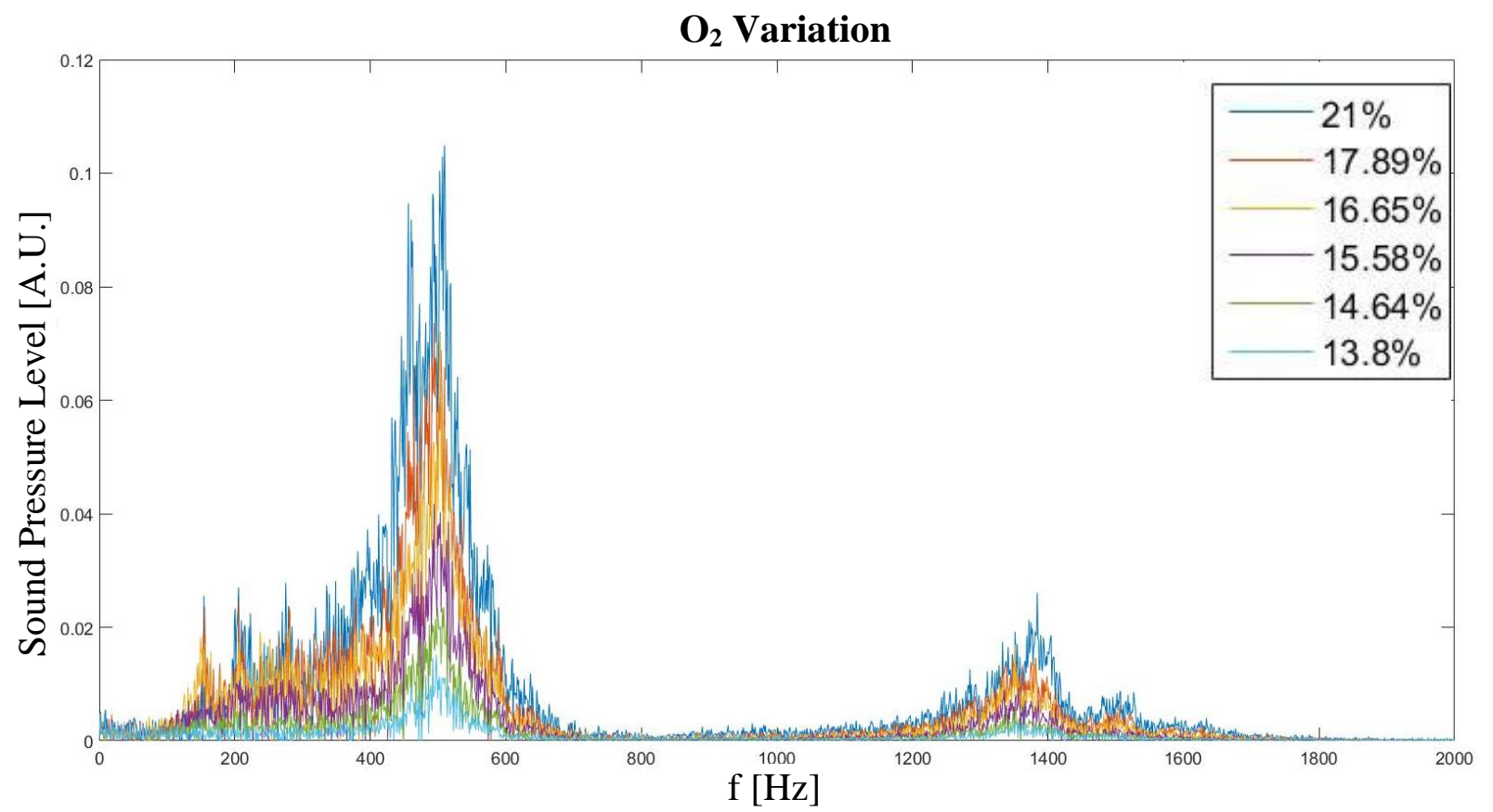

Figure 7. Acoustic frequency response for alrerent Oxygen concentrations with $\mathrm{N}_{2}-\mathrm{CO}_{2}$ dilution 
Figure 8

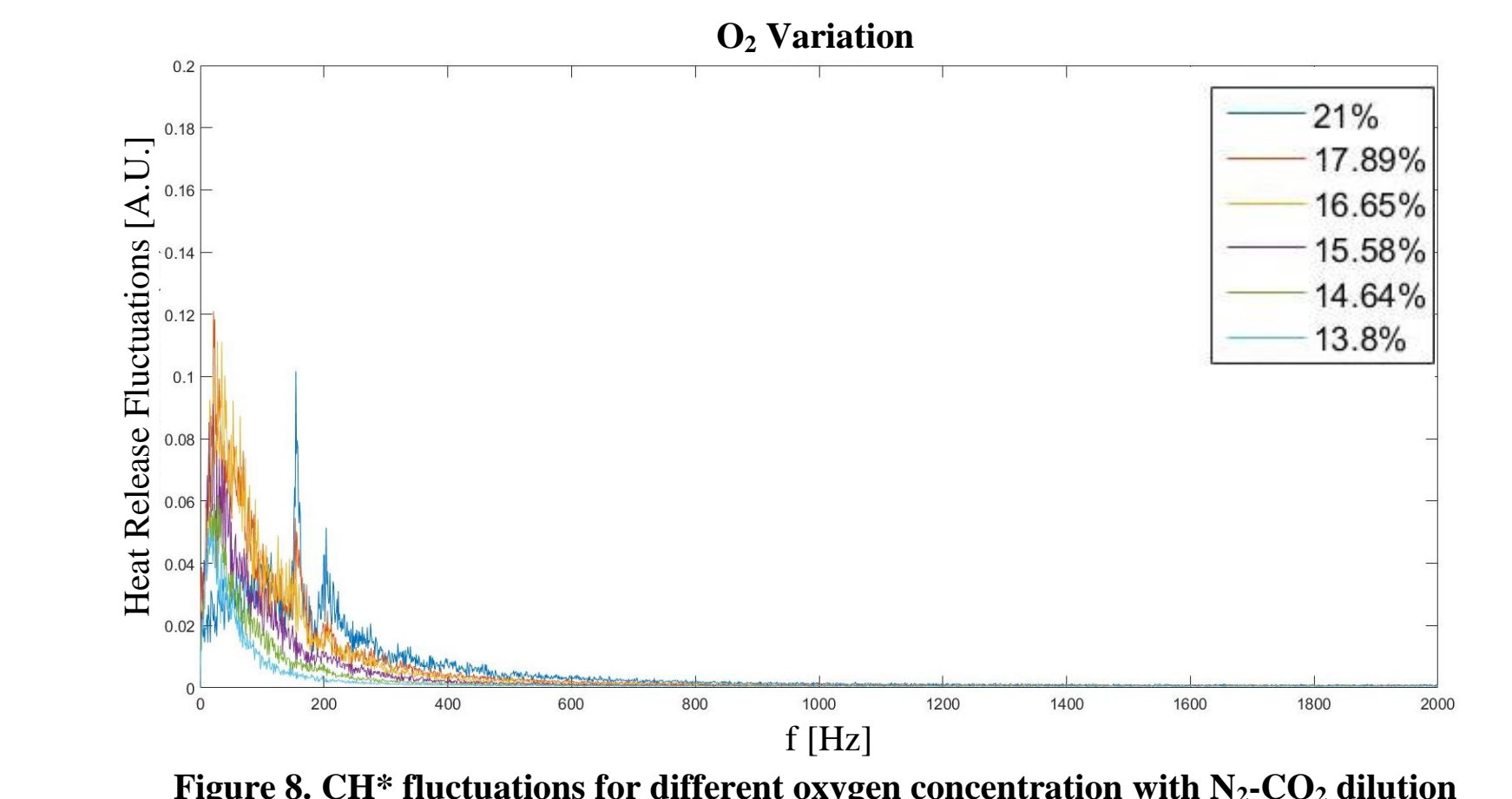

Figure 8. $\mathrm{CH}^{*}$ fluctuations for different oxygen concentration with $\mathrm{N}_{2}-\mathrm{CO}_{2}$ dilution

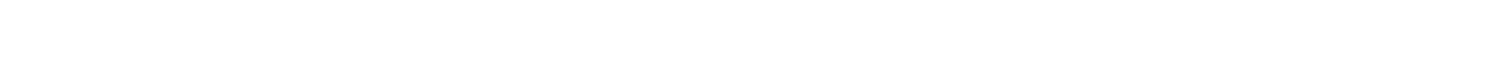

Fure 8

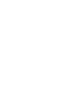

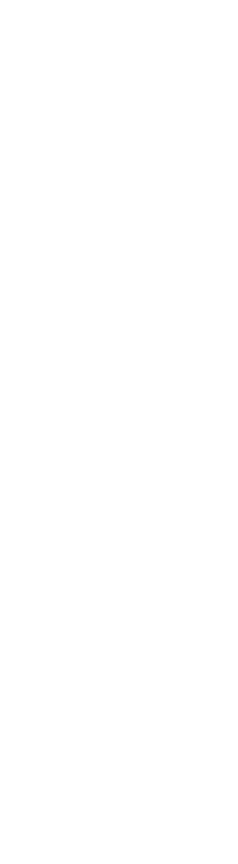

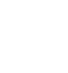
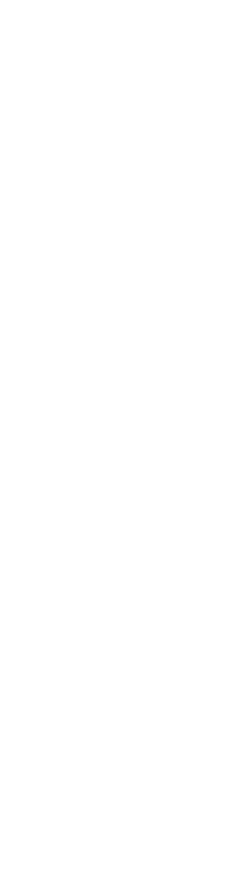

.

.

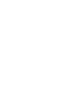



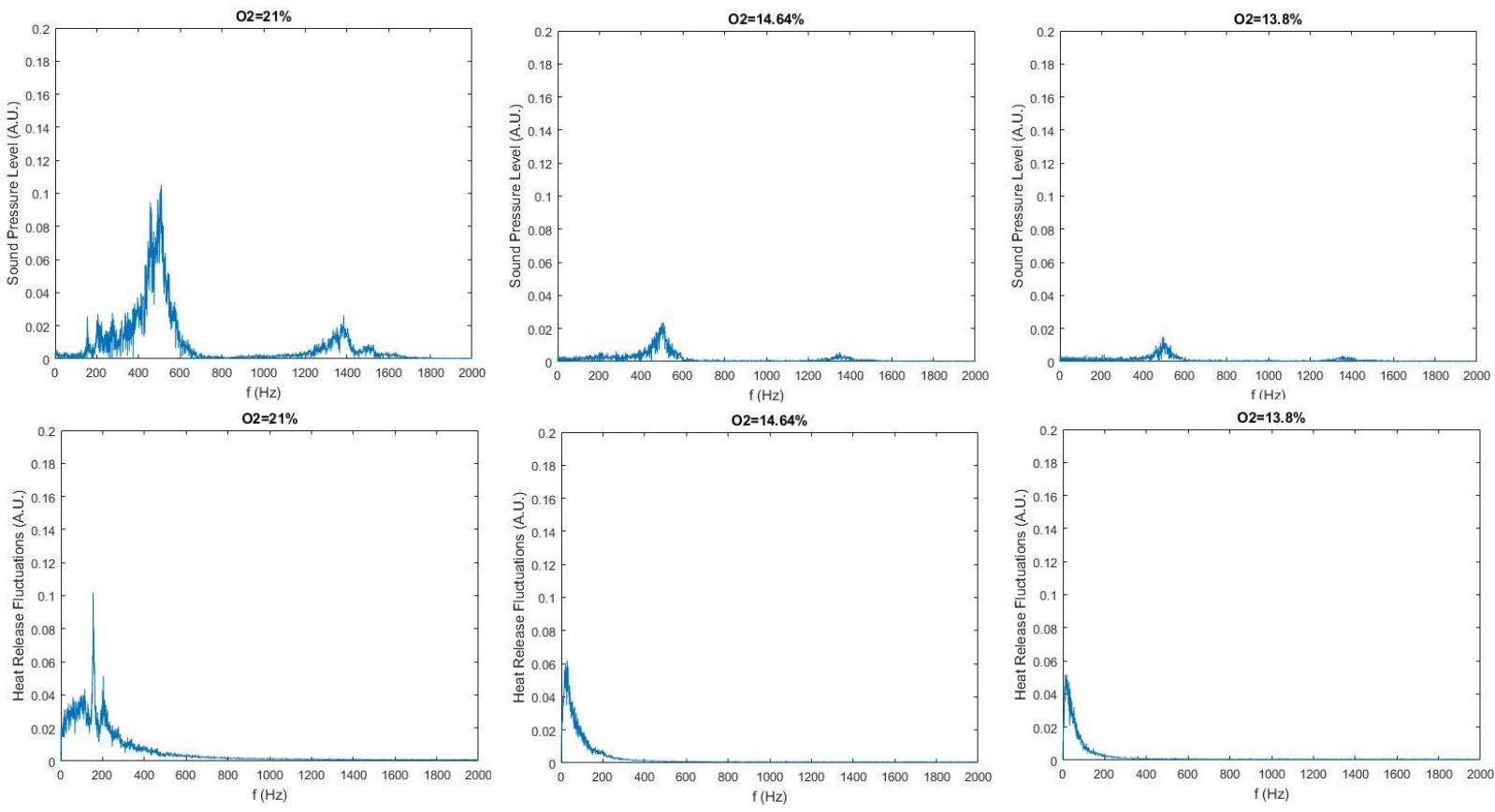

Figure 9. Acoustic signal (top) and $\mathrm{CH}^{*}$ fluctuations (bottom) for different oxygen concentration 


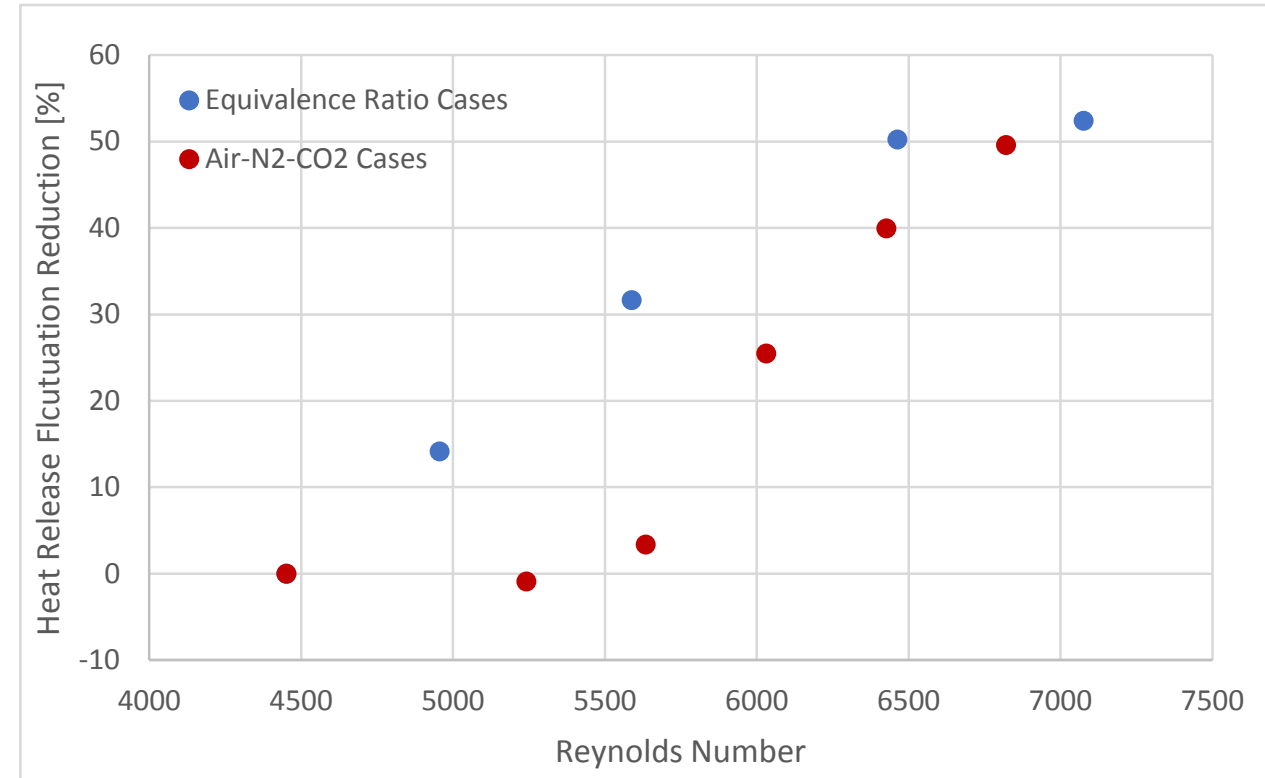

Figure 10. Percent reduction in heat release fluctuations for different equivalence ratios (blue dots, Re number increase with decrease in Phi) and oxygen concentration reduction cases (red dots, $R$ e number increase with decrease in oxygen concentration). 

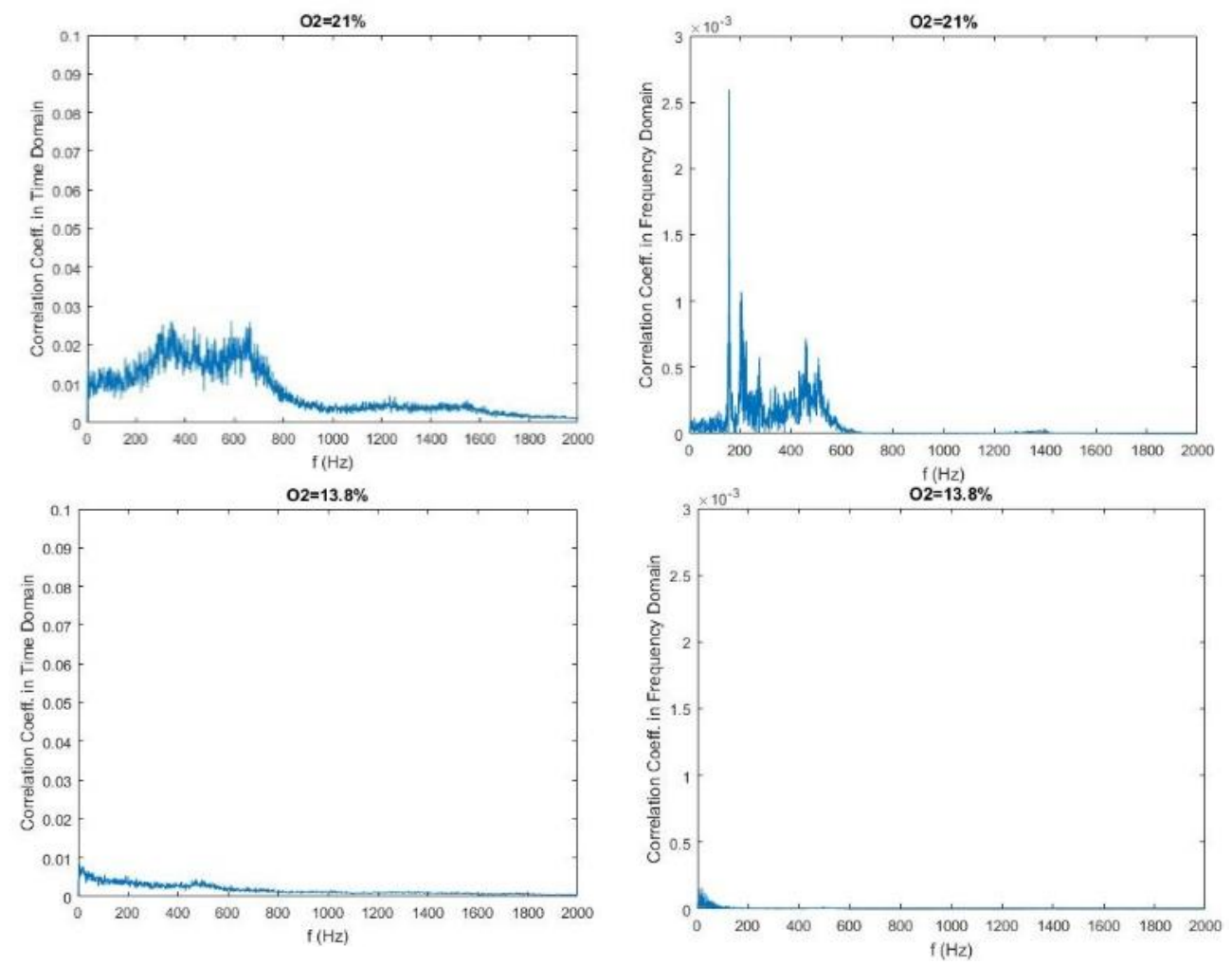

Figure 11. Correlation between acoustic signal and $\mathrm{CH}^{*}$ fluctuations calculated in time domain (and expressed in frequency domain, left) and calculated in frequency domain (right) 


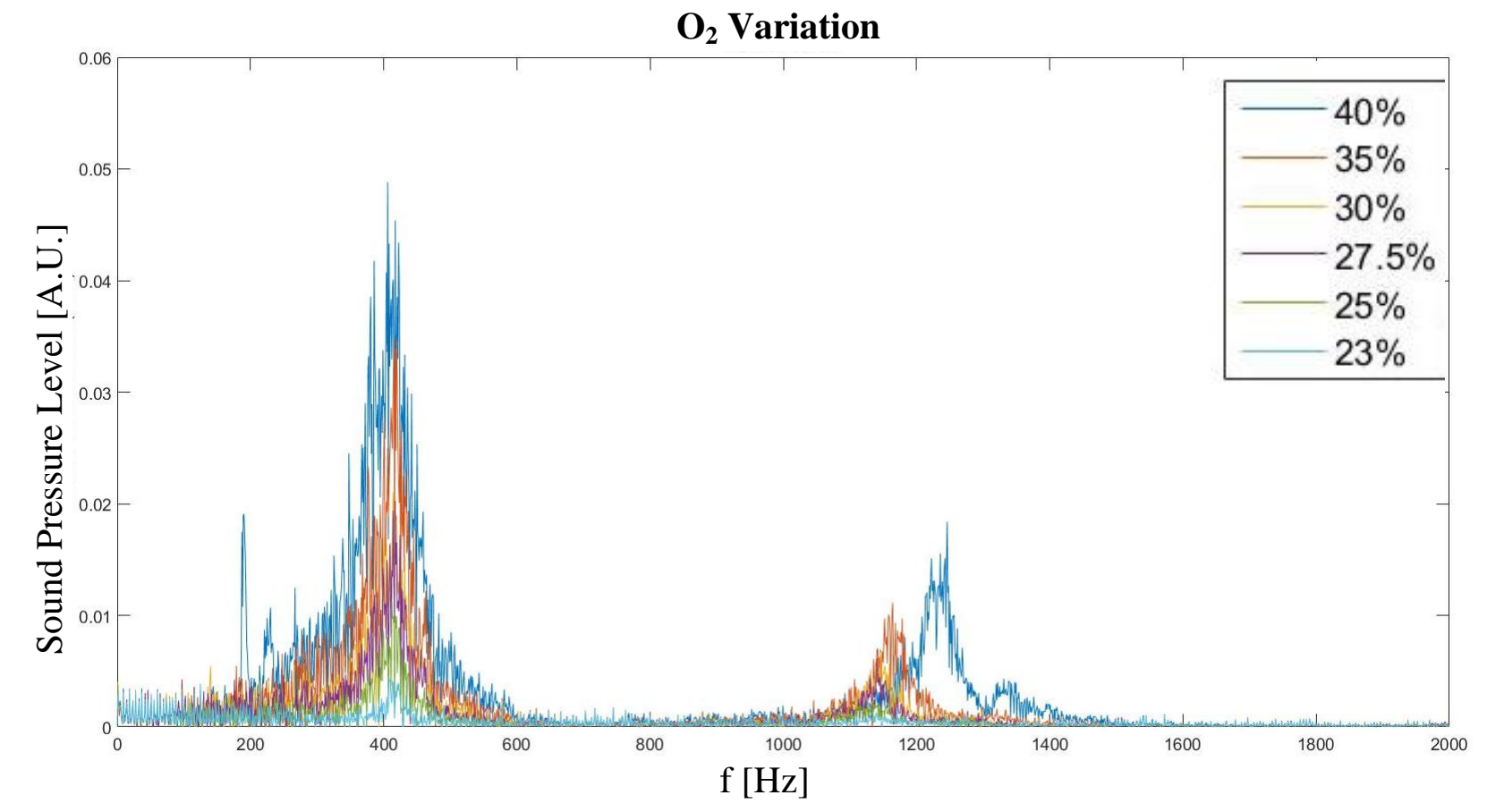

Figure 12. Acoustic frequency response for different oxygen concentrations in $\mathrm{O}_{2}-\mathrm{CO}_{2}$ mixture 


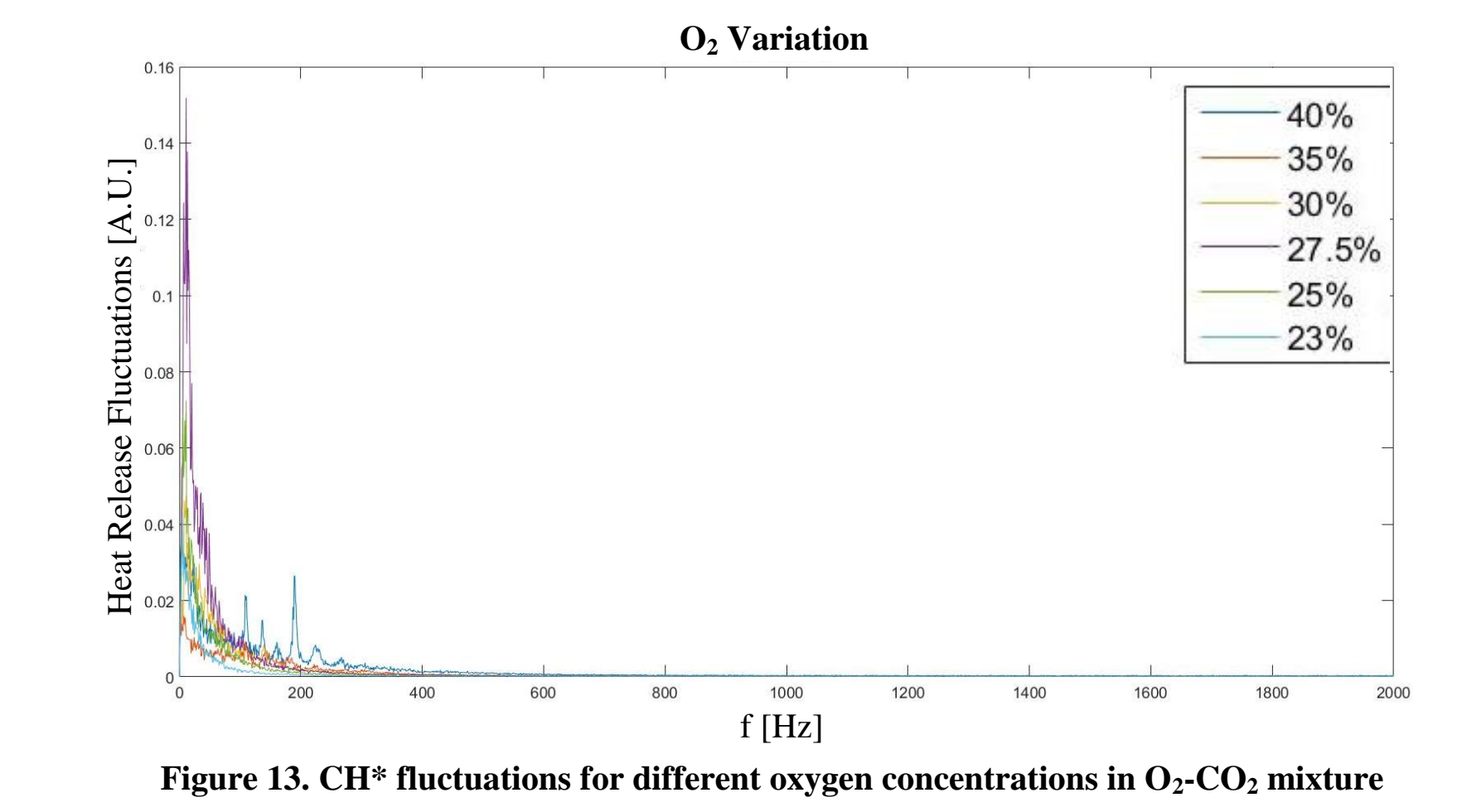

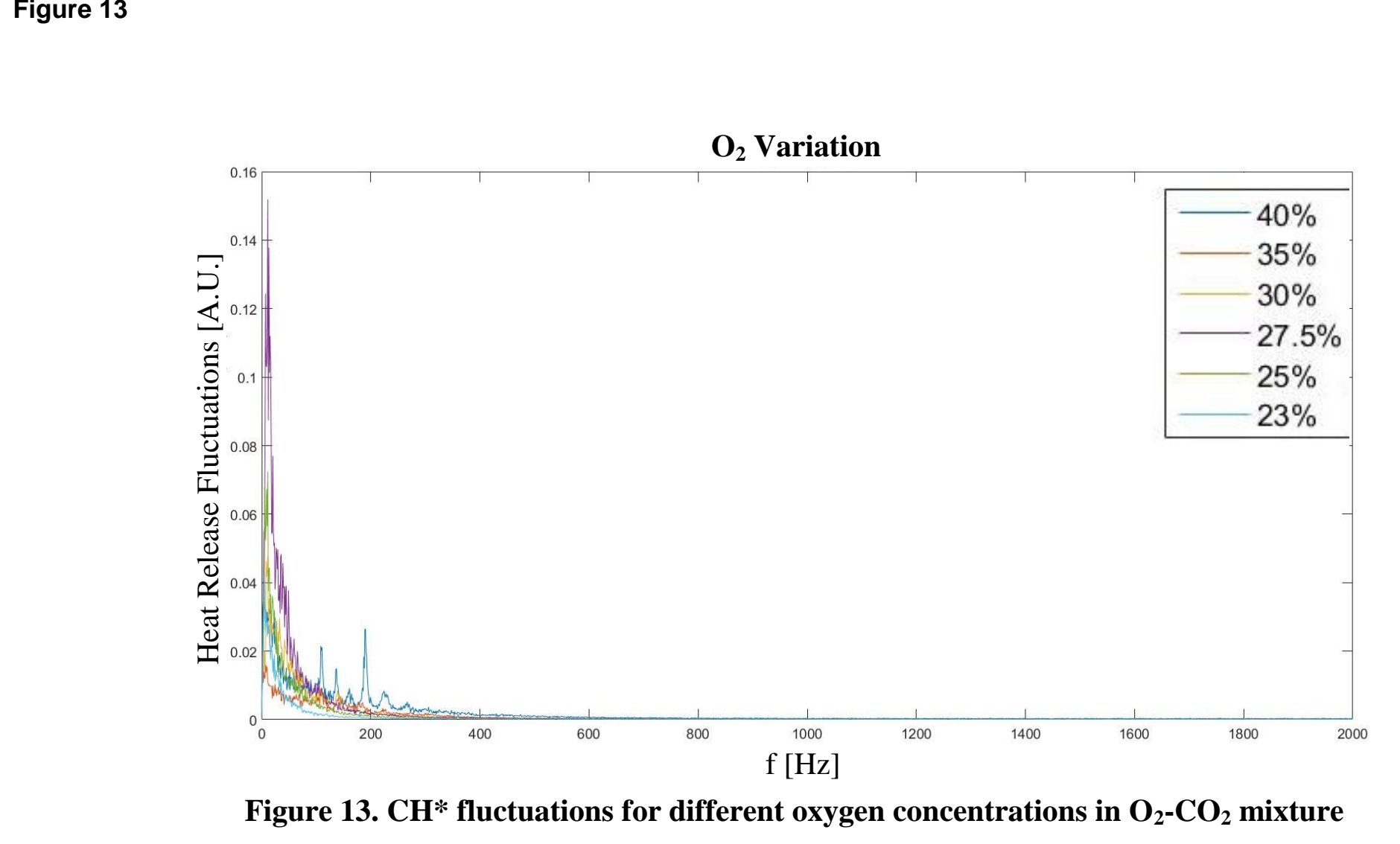
.

3

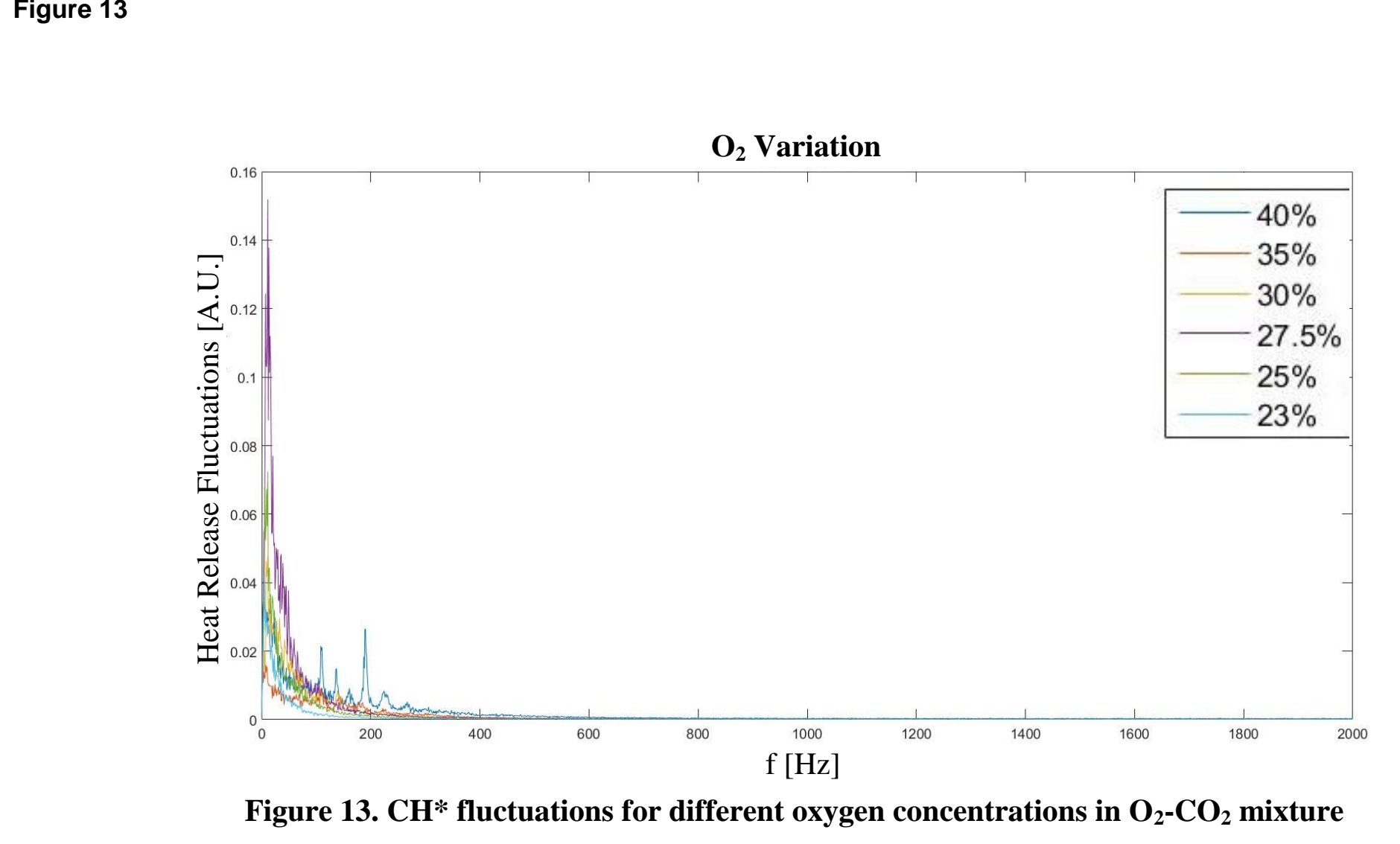
(a)

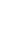




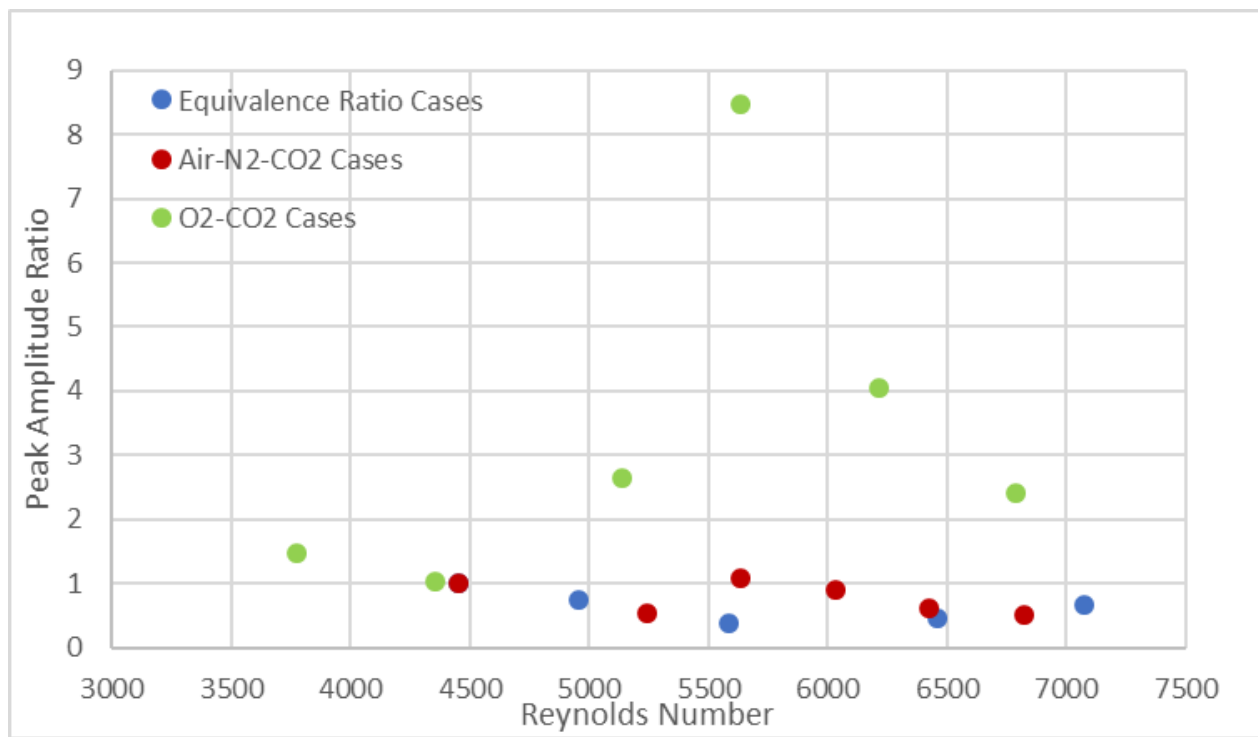

Figure 14. Peak $\mathrm{CH}^{*}$ fluctuations for the different equivalence ratios (blue dots, $\mathrm{Re}$ number increase with decrease in Phi), oxygen concentration reduction cases (red dots, Re number increase with decrease in oxygen concentration), and oxy fuel combustion case (green dots, Re number increase with decrease in oxygen concentration). 


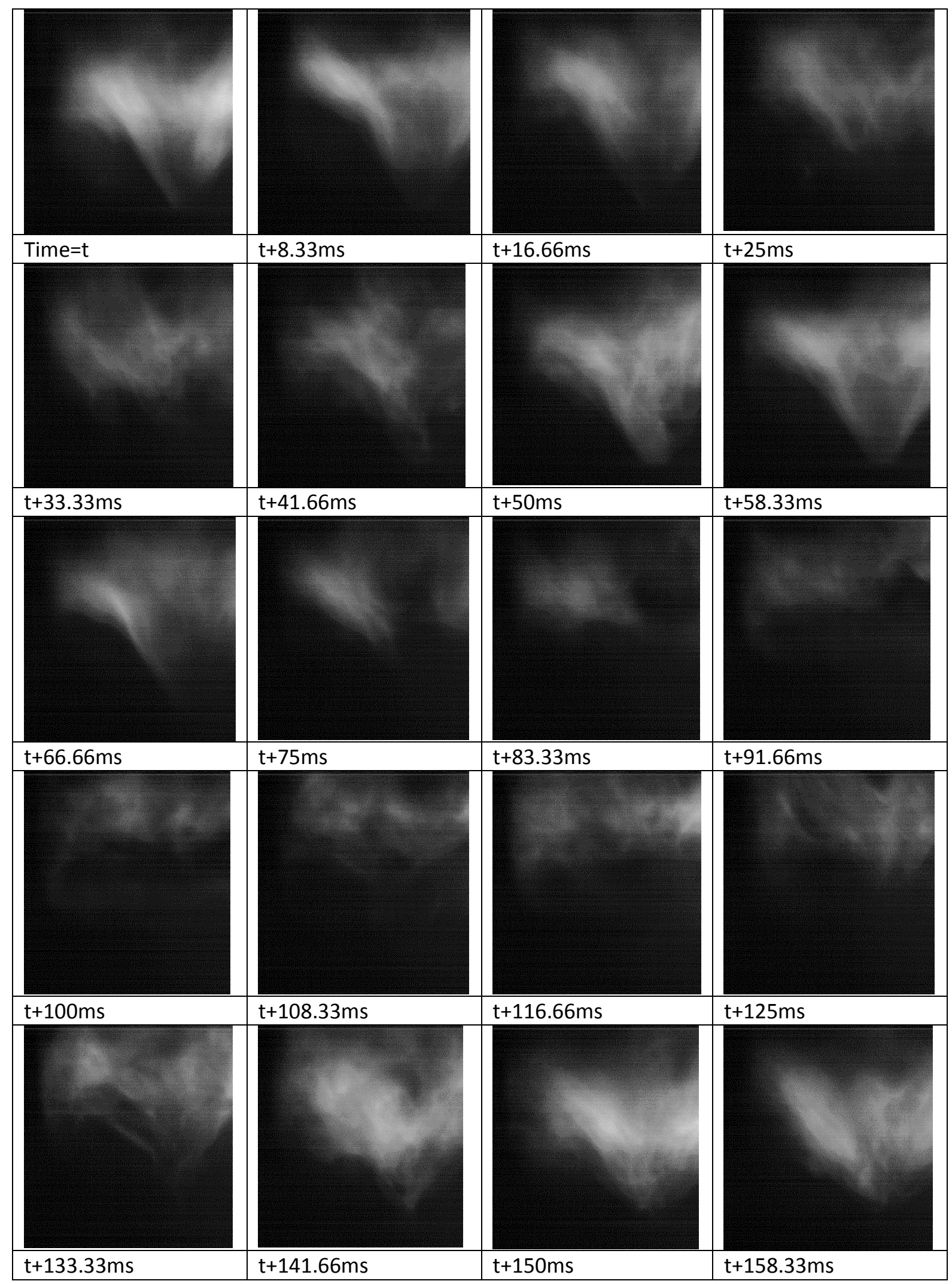

Figure 15. Flame visible fluctuation for oxygen concentration of $27.5 \%$ in $\mathrm{O}_{2}-\mathrm{CO}_{2}$ mixture 


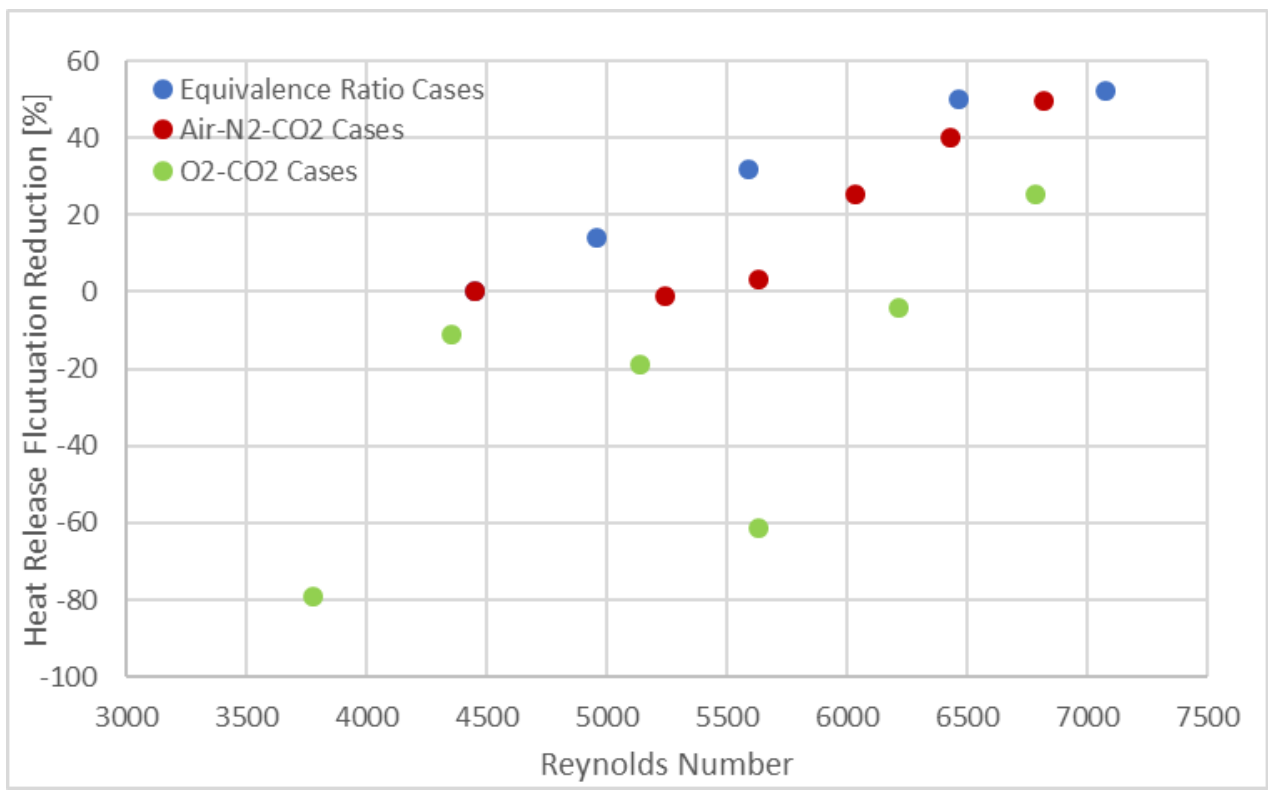

Figure 16. Percent reduction in heat release fluctuations for different equivalence ratios (blue dots, Re number increase with decrease in Phi), oxygen concentration reduction cases (red dots, Re number increase with decrease in oxygen concentration), and oxy fuel combustion case (green dots, Re number increase with decrease in oxygen concentration). 


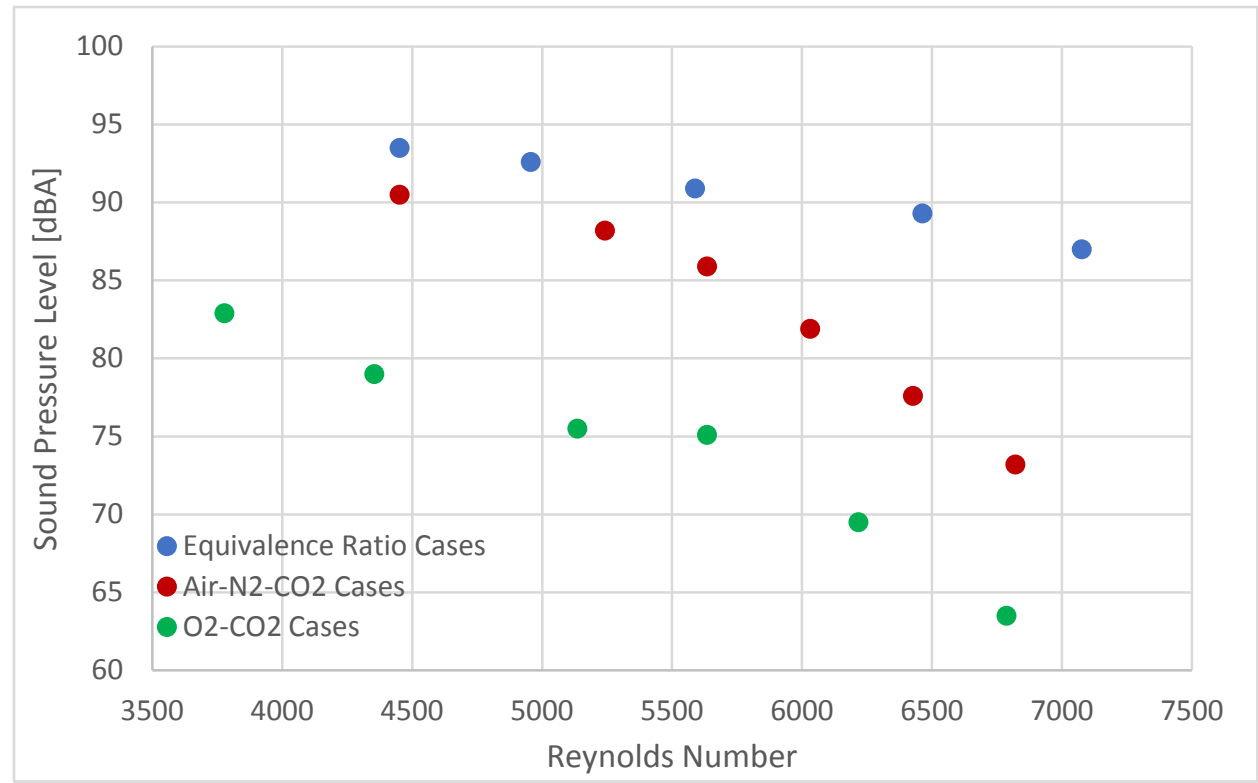

Figure 17. Total sound level for different equivalence ratios (blue dots, Re number increase with decrease in Phi), oxygen concentration reduction cases (red dots, Re number increase with decrease in oxygen concentration), and oxy fuel combustion case (green dots, Re number increase with decrease in oxygen concentration). 
Table 1. Experimental parameters for methane-air combustion

\begin{tabular}{|c|c|c|c|c|c|}
\hline \multirow{2}{*}{\multicolumn{2}{|c|}{$\begin{array}{c}\text { Equivalence } \\
\text { Ratio (Phi) }\end{array}$}} & \multicolumn{2}{|c|}{ Flowrates [1/min] } & \multirow{2}{*}{$\begin{array}{l}\text { Oxygen Conc. [\%] } \\
\text { in Oxidizer }\end{array}$} & \multirow{2}{*}{$\begin{array}{c}\text { Reynolds } \\
\text { Number (Re) }\end{array}$} \\
\hline & & $\mathrm{CH}_{4}$ & Air & & \\
\hline $\mathbf{1}$ & 0.9 & \multirow[t]{5}{*}{6} & 63.9 & \multirow[t]{5}{*}{21} & 4450 \\
\hline 2 & 0.8 & & 71.8 & & 4960 \\
\hline 3 & 0.7 & & 81.7 & & 5590 \\
\hline 4 & 0.6 & & 95.2 & & 6460 \\
\hline 5 & 0.55 & & 105 & & 7080 \\
\hline
\end{tabular}


Table 2. Experimental parameters for air-methane with $\mathrm{N}_{2} / \mathrm{CO}_{2}$ dilution

\begin{tabular}{|c|c|c|c|c|c|c|c|}
\hline & \multirow{2}{*}{$\begin{array}{c}\text { Equivalence } \\
\text { Ratio (Phi) }\end{array}$} & \multicolumn{2}{|c|}{ Flowrates $[1 / \mathrm{min}]$} & \multicolumn{2}{|c|}{ Diluents [l/min] } & \multirow{2}{*}{$\begin{array}{c}\text { Oxygen Conc. [\%] } \\
\text { in Oxidizer }\end{array}$} & \multirow{2}{*}{$\begin{array}{c}\text { Reynolds } \\
\text { Number (Re) }\end{array}$} \\
\hline & & $\mathrm{CH}_{4}$ & Air & $\mathbf{N}_{2}$ & $\mathrm{CO}_{2}$ & & \\
\hline 6 & \multirow[t]{6}{*}{0.9} & \multirow[t]{6}{*}{6} & \multirow[t]{6}{*}{63.9} & 0 & $\mathbf{0}$ & 21 & 4450 \\
\hline 7 & & & & 10 & 1.11 & 17.89 & 5240 \\
\hline 8 & & & & 15 & 1.67 & 16.65 & 5630 \\
\hline 9 & & & & 20 & 2.22 & 15.58 & 6030 \\
\hline 10 & & & & 25 & 2.78 & 14.64 & 6430 \\
\hline 11 & & & & 30 & 3.33 & 13.8 & 6820 \\
\hline
\end{tabular}


Table 3. Experimental parameters for oxygen-methane with $\mathrm{CO}_{2}$ dilution

\begin{tabular}{|c|c|c|c|c|c|c|c|}
\hline & \multirow{2}{*}{$\begin{array}{c}\text { Equivalence } \\
\text { Ratio (Phi) }\end{array}$} & \multicolumn{3}{|c|}{ Flowrates [1/min] } & \multirow{2}{*}{\begin{tabular}{|c|} 
Diluents [1/min] \\
$\mathrm{CO}_{2}$ \\
\end{tabular}} & \multirow{2}{*}{\begin{tabular}{|c|} 
Oxygen Conc. [\%] \\
in Oxidizer
\end{tabular}} & \multirow{2}{*}{$\begin{array}{c}\text { Reynolds } \\
\text { Number (Re) }\end{array}$} \\
\hline & & $\mathrm{CH}_{4}$ & Air & $\mathbf{O}_{2}$ & & & \\
\hline 12 & \multirow[t]{7}{*}{0.9} & \multirow[t]{7}{*}{6} & 63.9 & - & - & 21 & 4450 \\
\hline 13 & & & \multirow[t]{6}{*}{-} & \multirow[t]{6}{*}{13.42} & 20.2 & 40 & 3780 \\
\hline 14 & & & & & 24.9 & 35 & 4350 \\
\hline 15 & & & & & 31.3 & 30 & 5140 \\
\hline 16 & & & & & 35.4 & 27.5 & 5630 \\
\hline 17 & & & & & 40.2 & 25 & 6220 \\
\hline 18 & & & & & 44.9 & 23 & 6790 \\
\hline
\end{tabular}


Figure Captions
Figure Captions

Figure Captions
Figure Captions

Figure Captions

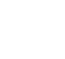

(1)

Figure Captions
\[ \text { Figure Captions } \]

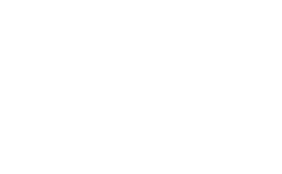

(1)

(1)

(1)

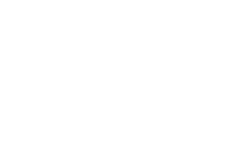

(1)

(1)

(1)

(1)

(1)

(1)

(1)

(1)

(1)

(1)

(1)

(1)

(1)

(1)

(1)

(1)

(1)

(1)

(1)

(1)

(n)

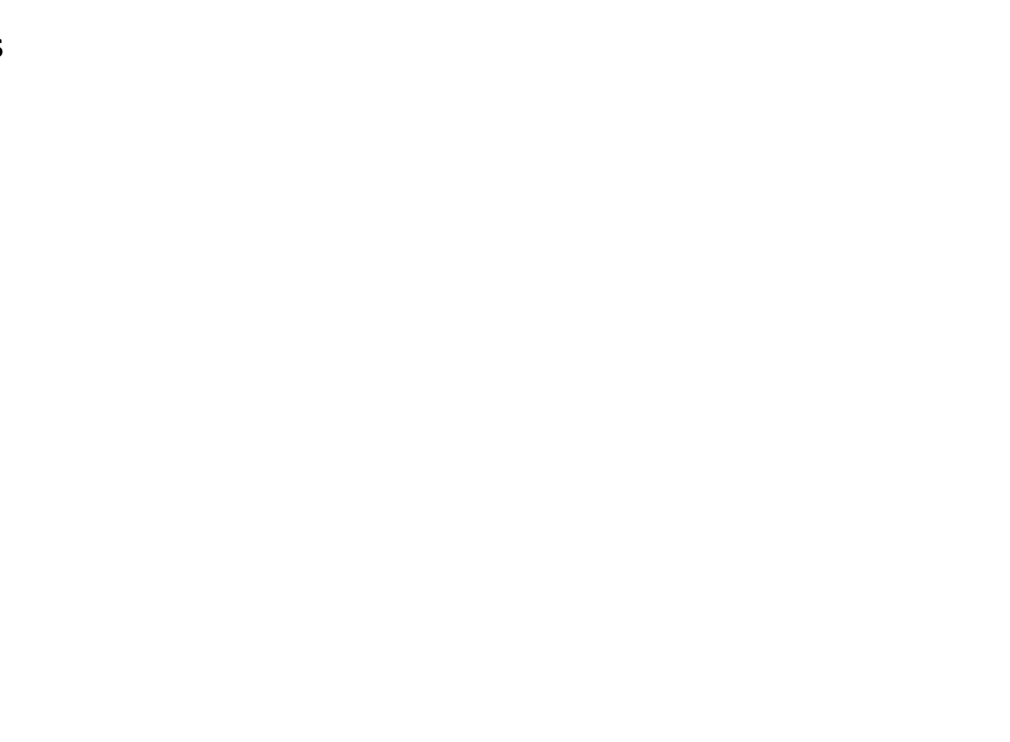

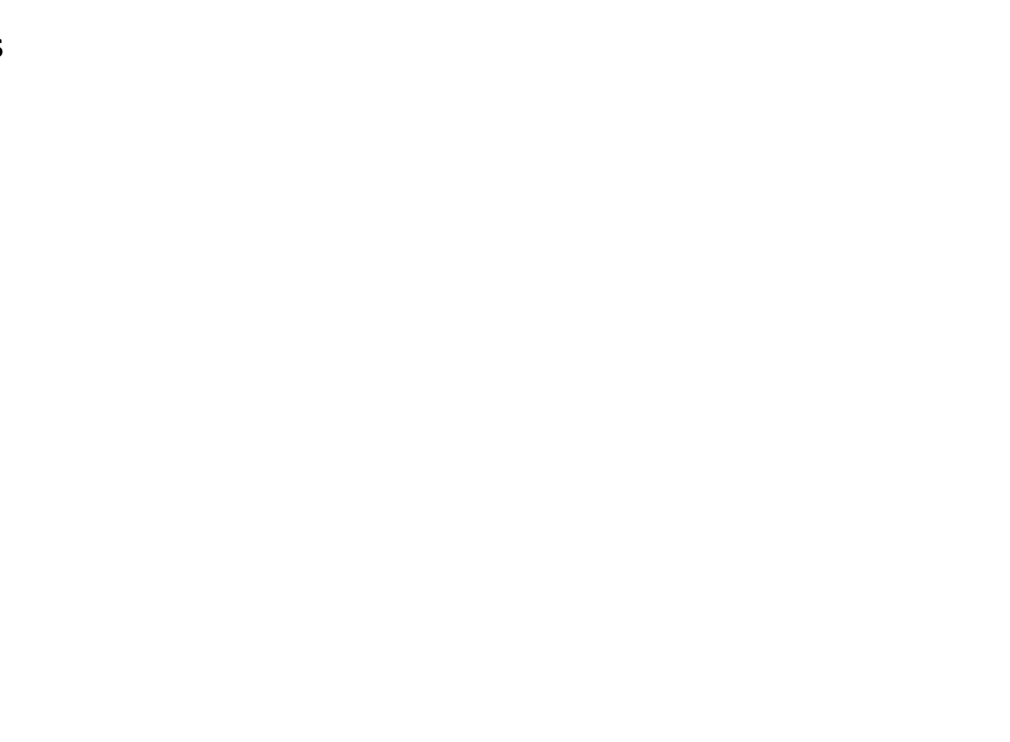

(20)

(20)

(20)

(20)

(20)

(20)

(20)

(20)

(20)

(20)

(2)

(20)

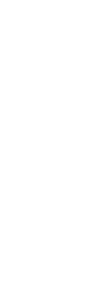

(20)

(n) 
Figure 1. Schematic of the experimental test rig

Figure 2. Flame behavior at lower oxygen concentration, $\mathrm{N}_{2}-\mathrm{CO}_{2}$ dilution [26]

Figure 3. Flame behavior at lower oxygen concentration, $\mathrm{CO}_{2}$ dilution for oxy-fuel combustion [43]

5 Figure 4. Acoustic frequency response for the different equivalence ratios examined

Figure 5. $\mathrm{CH}^{*}$ fluctuations for different equivalence ratios examined

Figure 6. $\mathrm{CH}^{*}$ fluctuations (left) and Acoustic signal (right) for phi=0.9 (top) and 0.55 (bottom)

Figure 7. Acoustic frequency response for different Oxygen concentrations with $\mathrm{N}_{2}-\mathrm{CO}_{2}$ dilution

Figure 8. $\mathrm{CH}^{*}$ fluctuations for different oxygen concentration with $\mathrm{N}_{2}-\mathrm{CO}_{2}$ dilution

Figure 9. Acoustic signal (top) and $\mathrm{CH}^{*}$ fluctuations (bottom) for different oxygen concentration

Figure 10. Percent reduction in heat release fluctuations for different equivalence ratios (blue dots, $R$ e number increase with decrease in Phi) and oxygen concentration reduction cases (red dots, Re number increase with decrease in oxygen concentration).

Figure 11. Correlation between acoustic signal and $\mathrm{CH}^{*}$ fluctuations calculated in time domain (and expressed in frequency domain, left) and calculated in frequency domain (right)

Figure 12. Acoustic frequency response for different oxygen concentrations in $\mathrm{O}_{2}-\mathrm{CO}_{2}$ mixture

Figure 13. $\mathrm{CH}^{*}$ fluctuations for different oxygen concentrations in $\mathrm{O}_{2}-\mathrm{CO}_{2}$ mixture

Figure 14. Peak $\mathrm{CH}^{*}$ fluctuations for the different equivalence ratios (blue dots, Re number increase with decrease in Phi), oxygen concentration reduction cases (red dots, Re number increase with

20 decrease in oxygen concentration), and oxy fuel combustion case (green dots, Re number increase with decrease in oxygen concentration).

Figure 15. Flame visible fluctuation for oxygen concentration of $27.5 \%$ in $\mathrm{O}_{2}-\mathrm{CO}_{2}$ mixture

Figure 16. Percent reduction in heat release fluctuations for different equivalence ratios (blue dots, Re number increase with decrease in Phi), oxygen concentration reduction cases (red dots, Re number increase with decrease in oxygen concentration), and oxy fuel combustion case (green dots, Re number increase with decrease in oxygen concentration).

Figure 17. Total sound level for different equivalence ratios (blue dots, Re number increase with decrease in Phi), oxygen concentration reduction cases (red dots, Re number increase with decrease in oxygen concentration), and oxy fuel combustion case (green dots, Re number increase with decrease in oxygen concentration). 
Table Captions

Table 1. Experimental parameters for methane-air combustion

Table 2. Experimental parameters for air-methane with $\mathrm{N}_{2} / \mathrm{CO}_{2}$ dilution

35 Table 3. Experimental parameters for oxygen-methane with $\mathrm{CO}_{2}$ dilution 